\title{
The nature, significance and influence of perceived personal experience of climate change
}

\author{
Joseph P. Reser and Graham L. Bradley, Griffith University
}

\begin{abstract}
The authors review relevant research published or reported between January 2014 and midyear 2019 following a previous review of this research landscape in 2014. The review findings suggest that the nature, significance, and influence of perceived personal experience of natural environment changes, conditions, and events deemed to be likely consequences of global climate change have been problematically conceptualized, researched, reported, and understood by many climate change scientists and by reporters of climate change science and their audiences. The nature, psychological significance, and psychological adaptation and issue engagement influence of personal experience of perceived environmental manifestations of climate change are arguably central considerations with respect to the human dimensions of climate change. These matters encompass public understanding of climate change science, both internal and external adaptation processes, the psychological impacts of the ongoing stressor of climate change, and issue engagement and behavioral change. It is increasingly necessary that existing issues with discipline-based assumptive worlds, constructs and measures - and often unclear research and policy questions and objectives - be identified, clarified, and addressed. This particularly matters when researchers and policy makers are addressing public risk perceptions, understandings, and responses to global climate change, ideally to inform and enhance policies directed at climate change mitigation and adaptation, or alternatively framed, public issue engagement and 'psychologically significant' as well as 'environmentally significant' behavioral change.
\end{abstract}




\section{Introduction}

There has been an important discussion and debate about the nature, extent, significance, and influence of personal 'experience of climate change' over the past decade across the social and behavioral sciences and the humanities (e.g., ${ }^{1-8}$ ). This has reflected, in part, parallel debates about the extent and underpinnings of public acceptance or 'belief' regarding anthropogenic climate change, how best to communicate with and engage publics regarding climate change, the nature of environmental risk perception and response in the context of climate change, and the unfolding and increasingly dramatic local and global biophysical environmental changes, events, and conditions attributed to climate change (e.g., $\left.{ }^{8-19}\right)$. The nature, scientific status, and psychological and issue engagement significance and influence of individuals' perceived exposure to and personal experience of 'climate change' have been underlying but often implicit considerations across this research endeavor (e.g., 6, 17, 20-29).

The objectives and scope of this review were to examine a representative sample of research articles, published between 2014 and 2019, in which authors have examined the nature, extent, significance, and issue engagement influence of personal experience of environmental changes, conditions, or events considered to be probable consequences of climate change. A second major objective was to identify and address underlying considerations and issues which are arguably undercutting credible and crucial advancement and much-needed multidisciplinary alignments in this research landscape.

This review follows an earlier review of research with a similar focus across a comparable period of time ${ }^{6}$. Our previous review was partly motivated by ongoing debate with respect to 'seeing' versus 'believing' in the context of climate change, and whether the seeming frequency of such reported experience was due to motivated reasoning rather than direct encounters and experience driving acceptance of the reality of climate change and issue engagement. This theoretical and conceptual debate had, and still has, strong political and policy implications. That review identified only four articles that assessed self-reported personal experience of perceived manifestations of climate change, and hence was a finegrained examination of just these four articles, not a review of the broader literature that reports research into perceived experience of climate change at an individual level. From that review, little could be seen as major findings because of the diversity of, and other inherent concerns with, the reviewed studies. The current review thus examines a broader and more recent set of research studies which have been presented as, or would reasonably be understood to be, focusing on 'personal experience of climate change'. This current status quo requires collective reflection, resolution, and some degree of cross-disciplinary 
standardisation of language and methodologies to enhance research in this area and to ensure a fuller appreciation and application of research findings . In this article we are using the term 'significance' to refer to the individual level psychological significance and impact of personal encounters with perceived manifestations of climate change, i.e., the experienced meaningfulness, importance, and implied consequence of what has particularly caught one's attention, and emotional and reflective engagement, while in and experiencing a natural environment setting change, condition, or event (e.g., unusual vegetation or wildlife presence or absence, phenological changes, strange weather, flood/drought severity). This use and meaning of the term is in contrast to statistical significance and behavioral 'environmental significance'. We also refer to both personal experience and environmental transactions in what follows as these terms reflect a more accurate and encompassing environmental psychology, environment-behavior, framing of individual-environment dynamics and accords with geographers' notion of 'situated phenomena' (e.g., ${ }^{30-32}$ ).

Research addressing and reporting personal experience of climate change-attributed environmental changes, conditions, events, and their impacts has been hampered by an often confusing, cross-disciplinary, discourse and language, and research practice. Reasons include:

- not situating the research, theory, and approaches advanced with respect to authors' differing disciplinary perspectives and the language and constructs used,

- not clearly defining and operationalising core constructs and differing levels of analysis,

- the differing definitions of 'climate change' (Kyoto protocol/IPCC)

- the common treatment of extreme weather events as proxy manifestations of climate change,

- rarely clarified differentiation between exposure and experience,

- the problematic equating of residential location with both exposure and experience,

- the neglect and liminal status of virtual and vicarious exposure and experience,

- the often implicit or explicit dismissal of self-reports, perceptions, and phenomenological accounts generally, on ostensible 'empirical' grounds,

- the consequent questioned legitimacy, credibility, and scientific status of research respondent accounts of personal encounters with natural environment changes, conditions or events deemed to be probable manifestations of global climate change. (e.g., $2,6,8,33-36)$. 
In the review which follows we have examined those research articles and reports which are presented as, or would be understood by most readers as, studies and discussions of the nature and influence of direct personal experience of global climate change, or extreme weather changes, events, or conditions effectively treated as de facto manifestations of climate change, and the implications and putative influence of such experience on beliefs/acceptance, policy support, and/or overt behavioral engagement with respect to climate change. We use the phrase 'perceived personal experience of climate change' (PPEOCC), to refer to personal encounters with and experience of salient natural environment changes, conditions, or events deemed by research respondents to be likely manifestations of global climate change. While we have not included in our sample research studies focusing on the nature, significance, or influence of virtual or vicarious exposure to or experience of climate change, we briefly consider such experience, as indirect (e.g., multimedia) exposure and experience undoubtedly influences perceived personal experience of climate change (e.g., ${ }^{37-40}$ ).

Clearly there are many types of perceived personal encounters with, and reported experiences of, global climate change that are relevant to this paper. Two of the most obvious and prevalent of these are:

- individual (or small group) encounters in natural environment settings/contexts whether in backyard gardens, parks, rural settings, or protected areas in which a noteworthy feature, aspect, or event captures one's attention, sense-making, and reflections/feelings;

- instances of extreme or unusual weather events, conditions, and/or regional impacts of such events and conditions, experienced by individuals resident in or spending time in affected areas.

\section{Perceptions and 'reality'}

A fundamental philosophical, psychological, and cross-cutting 'human dimension of climate change' research which is rarely acknowledged or addressed is that of the conceptual and 'hard science' distinctions between, and the respective empirical and epistemological status of, an objectively real world of individual-natural environment transactions and encounters, as contrasted with individual level perceptions, sense-making, and experiences in natural environments. Also of central importance is the nature and status of 'virtual' exposure and experience via the ubiquitous new media 'information environment', continually reporting and representing both the phenomenon and risk domain of climate change and 
associated natural environmental changes, conditions, events, and risks increasingly attributed to climate change (e.g., ${ }^{41-46}$ ). A further recurring issue is whether reported personal experiences of perceived climate change manifestations might be alternatively understood and conceptualized as instances of motivated reasoning/confirmation bias and/or prone to other 'subjective' limitations and heuristic biases (e.g., 2, 5-7, 47-49). These discussions concerning the nature and importance of PPEOCC also reflect but largely ignore an extensive backdrop of natural history writings, environmental education research, environmental psychology perspectives, natural resource and human ecology restoration and management science, environmental risk perception research, place attachment and meaning research and writing, and philosophical and psychological studies of the nature of perception and experience (e.g., $\left.{ }^{50-61}\right)$.

A revealing example of confusion in these intersecting research literatures is that of the nature and conceptualisations of environmental risk perception as distinct from environmental risk assessment. 'Risk perception' is inherently about individuals' phenomenological perceptions, sense-making, and understandings, with this 'reality' central to the contested credibility and validity of self-reports regarding such individual-environment encounters and experiences (e.g., ${ }^{62,63}$ ). Environmental risk perception encompasses perceived human risks both from and to natural environments. 'Environmental risk assessment' is a more specialized, expert judgement-driven, formal process, often entirely divorced from a lay individual's 'subjective' perceptions and understandings of the nature, extent, and seriousness of risks from and to one's known and familiar natural environment (e.g., $\left.{ }^{23,64-69}\right)$.

Importantly, even professionally-driven risk assessment processes ultimately rest on human judgements. Hence when academic discussion or research undertakings are addressing respondents' perceived and reported personal experiences of global climate change, this is the data, the evidence, being considered, irrespective of whether the local incident or phenomenon would be judged by biophysical climate change science experts to be a substantive risk attributable to global climate change. Environmental risk perception is also, quite logically, an aspect and product of sense-making when encountering the changed, the anomalous, the disturbing in one's known and familiar natural environment, with cognitive appraisals and causal attribution - rarely resolution - a core component of sense-making (e.g., ${ }^{70-76}$ ). Such sense-making in the context of personal encounters with environmental changes and events attributed to climate change can constitute particularly salient, personally significant, witnessing events, in this case of a grave, planet-altering, indeed existential risk 
(e.g., ${ }^{45,77-83}$ ). As Weber ${ }^{84}$ also notes, the U.S. National Science Foundation (NSF) Committee on the Human Dimensions of Climate Change, in its ground-breaking 1992 report, "divides human response to global changes into a hierarchical set of seven interacting systems, with the most fundamental system being 'individual perception, judgement, and action"” ( $\left.{ }^{84, p . ~ 315 ; 85, p 5}\right)$. The status and fundamental importance of individual level perceptions and personal experience of climate change has not altered in the interim following the NSF report (e.g., ${ }^{8,15,83,86}$ ).

We argue that it is not possible to make progress in defining dangerous climate change, or in developing sustainable responses to this global problem, without recognising the central role played by social or individual perceptions $\left({ }^{23, \text { p. } 11}\right)$.

\section{Public versus climate change science understandings}

Central to this consideration of the nature, significance, and influence of reported personal experience with seeming local evidence of climate change is the question of national and global publics' general understandings of 'climate change', as compared to formally accepted climate change science accounts and definitions. It can be cogently argued that current public understandings of 'climate change' in most developed countries is that of global, anthropogenic, atmospheric system change - and societal, biodiversity, and ecosystem system consequences. This understanding corresponds, in essence, with the definition of 'climate change' by the United Nation's Framework Convention on Climate Change, i.e., "a change of climate that is attributed directly or indirectly to human activity that is in addition to natural climate variability observed over comparable time periods" ${ }^{87-89}$. While most social and behavioral scientists, and science journalists and writers, along with the public, accept this Kyoto Protocol definition, many national and international physical and natural science bodies (e.g., ${ }^{90}$ ) fundamentally changed this Framework Convention definition to encompass and apply to any "natural internal processes or external forcings ... in the composition of the atmosphere" 91.

This definitional divide creates serious communication and policy problems - and research challenges - in that the phenomenon and risk domain of climate change, from a public understandings and public discourse perspective, and hence research survey consideration, includes this crucial human causal contribution or 'forcing' as the defining and differentiating feature of anthropogenic climate change (e.g., ${ }^{6,45,59,88,92}$ ). This important anthropogenic, 'hybrid', character of global climate change, along with the scope and multiple associated meanings which accrue to such a grave and global environmental risk (e.g., dread, stigma, the unknown, species and ecosystem loss, catastrophic human deaths) is 
strongly evidenced by over three decades of environmental risk perception and meaning research (e.g., ${ }^{57-59,88,93-97}$ ).

What does the general public make of the global warming problem? How does the public view the risks entailed by greenhouse emissions? What is the correspondence, if any, between the scientific picture and the public view, between the professional assessment of risk and lay public's perception? While considerations of the social, ethical and cultural context for evaluating the long term risk of climate change are emerging, relatively little attention has been paid to psychological aspects (23, p. 104).” (98, p. 1).

The language and multiple labels being used to distinguish 'human-influenced' environmental risks, phenomena, and events/impacts from 'natural' environmental risks, phenomena, and events/impacts remains confusing and dynamic as we enter the Anthropocene. Reference to 'extreme weather events' is encompassing but reasonably clear, though the matter of attributed human causal influence is seldom or satisfactorily addressed or clarified in particular contexts 99,100 . 'Disaster' labels include natural disasters, technological disasters, hybrid disasters, and natech disasters, with hybrid disasters being the most general descriptor for events or circumstances reflecting combined natural and human causation. Potentially adding confusion, extreme weather events are often simultaneously referred to as natural disasters in research contexts relating to personal experience and human impacts.

In a number of ways the phenomenon and risk domain of climate change differs dramatically from these descriptors and categories in that this is a global phenomenon and risk domain, existential in nature, planet system changing in consequence, likely now present for millennia, and constituting an ever-present environmental stressor. But 'climate change' also shares the emotional valences and meanings of numerous other hybrid risk domains, with respect to stigma, blame, catastrophic consequences, and interference with nature. When participants in research surveys respond to questions relating to equivalents of PPEOCC, this human causal attribution is a critical, sense-making, response-determining, 'tampering with nature', factor strongly differentiating climate change from other 'natural' environmental risk domains (e.g., $45,72,94,96,101,102)$. However, the most salient point in the context of researching perceived personal experience of climate change is that while many extreme weather events are likely to be influenced by climate change, they must be personally perceived as probable manifestations climate change to constitute 'perceived personal experience of climate change'. This criterion has seldom been addressed or applied in the research we have 
reviewed, previously and presently. It is noteworthy that, in multiple recent research surveys that include items addressing causal attributions for climate change, over $85 \%$ of respondents select options indicating the cause was either human activity mainly or entirely (e.g., ${ }^{25,88,103-}$ $\left.{ }^{108}\right)$.

How is personal experience of climate change conceptualized, operationalized, and reported in social and behavioral sciences research contexts?

The motivational and psychological impact relevance of 'personal experience' in the context of climate change risk perceptions, understandings, and responses has been well recognized over the past decade (e.g., 1, 2, 5-7, 9, 20,31, 109-115). Yet definitional and operational specification of what is meant and encompassed by personal 'experience' remains a crucial matter in making sense of research reports and arguments. Although many studies have documented the important influence of 'experience' on risk perceptions, and the effect of risk perceptions on preparedness and mitigation behaviors ${ }^{5,116-118}$, the linkages are complex, varying in strength and even direction in some cases (e.g., ${ }^{119}$ ). The importance of experience depends in part on its location, intensity, duration, type, and how it is defined ${ }^{120,121}$. For natural hazards for example, personal experience has often been limited to witnessing a specific event or, alternatively, to suffering substantial losses from it. ${ }^{122 .}$

Recent overview articles relating to personal experience of climate change "consider 'experience' in a very broad locational sense - as 'geographic' exposure, for example, residing in an area where local climate conditions have changed over the past five years" (e.g., ${ }^{2,4,123-126}$ ). However, this take on 'experience' and underlying levels of analysis effectively ignore the nature and dynamics of individual level experience, risk perception, sense-making, and psychological responses and impacts. This locational, geographic exposure, consideration of 'experience' also encompasses experiences of perceived but more gradual climate change impacts that occur over seasons, years, and even decades (e.g., $\left.{ }^{69,127}\right)$. Also routinely ignored is the very distinctive nature of this global, hybrid, and ongoing environmental stressor character of this climate change risk domain, its social constructions and representations ${ }^{93,96128-31}$, and the realities of virtual and vicarious exposure through a global 'information environment' (e.g., ${ }^{45,132}$ ). Again, it is a widespread researcher view supported by ample evidence that understanding the anthropogenic causes of climate change is the strongest predictor of climate change risk perception (e.g., ${ }^{6,102,133,134}$ ).

Much of the conventional logic of these many approaches to researching personal experience of climate change are captured in a reflective publication by Egan and Mullin ${ }^{135}$. 
However, research about the effects of personal experience on attitude formation almost always suffers from two threats to inference. First individuals are usually exposed to experience - or in fact may select into these experiences - in non-random ways that are correlated with the attitudes hypothesized to be dependent on the experiences. Second, most research relies on survey respondent self-reports of experience. These reports are not only unreliable; they may also be the consequences of specific attitudes about politics and public affairs, rather than bias-free measures of their causes. ... Our research strategy is straightforward: we merge local weather records with geocoded data collected from five nationally representative sample surveys. ... In short, we exploit the fact that changes in local temperature assign individuals nearly at random to experiences that they may choose to interpret as evidence for or against global climate change $\left({ }^{135, \text { p. }}{ }^{796}\right)$.

There are many other more recent researchers who have basically adopted this strategy (e.g., ${ }^{125,136,137}$ ). This logic and accompanying operationalizations unfortunately simply misses the nature, meaning, and significance of personal experience generally and PPEOCC, and dramatically attenuates the encompassing spectrum of possible natural environment encounters and experiences.

\section{The current climate change research landscape addressing personal experience.}

To gain an overview of research published in the period from January 2014 to June 2019, we searched the literature for studies addressing personal experiences of climate change, or studies that link other kinds of personal experiences to climate change-related beliefs, attitudes, or behaviors. We uncovered almost 100 empirical studies, plus thirteen review papers that related to the topic of climate change-related experiences, and a small number of conceptual papers and monographs. From this set, we selected 36 papers reporting empirical research that seemingly represent the breadth and diversity of the research landscape, and we conducted a thorough critical review of these 36 studies. Selection of these papers was purposive, rather than exhaustive, with the aim of ensuring the availability for review of a cross-section of articles in terms of (a) outlets/journals. (b) countries of origin, (c) author(s) disciplinary background(s), (d) types of experience investigated and means of assessing these experiences, (e) dependent or outcome variables, and (f) research (data collection and analysis) methods. The online supplementary materials accompanying this paper contain tables summarising key aspects of the selected studies. Additional details relating to this review are available upon request from the second-named author. This section highlights key points from our review. 


\section{Description of the Studies}

Most of the 36 studies were conducted in the USA, although nine other nations were represented, and one study ${ }^{138}$ included data from 24 nations. The studies were published in 18 different journals, and were authored by researchers from a range of disciplines.

Theoretical and/or other conceptual foundations underlying the research were seldom stated, and none of the papers provided a detailed definition or discussion of the concepts of experience or personal experience.

Most studies used survey (questionnaire-based) methods, with one in three complementing these with data drawn from meteorological or similar databases. Other methods included interviews, experiments, and analyses of archival data. Three studies used mainly qualitative methods. No study fully captured both the qualitative and quantitative dimensions of experience. Sample sizes varied from 43 to almost 15,000 participants, with the two studies that used online users or messages as the unit of analysis having samples in excess of one million. Data analytic techniques varied with study aims and design, with regression-based techniques most commonly employed.

The studies are roughly divisible into three broad categories based on the means used to assess the core exposure or experience variable(s). In the first category, thirteen studies 4 , 107, 125, 136, 137, 1391-146 used various meteorological databases (e.g., from the US National Oceanic and Atmospheric Administration, or the US National Climatic Data Center) to extract information pertaining to weather conditions, extreme weather events, natural disasters, and/or climatic patterns in participants' place (e.g., county or zip code) of residence. A further four studies adopted what might be termed a 'group comparative' approach that involved taking advantage of unusual weather patterns occurring at particular times in particular regions either to compare residents before and after these events, or to compare samples of residents of affected and unaffected areas. The remaining 19 studies assessed experience through self-reports. These reports were obtained either through face-toface interviews ${ }^{147-151}$, telephone interviews ${ }^{152}$, paper/postal questionnaires ${ }^{153-156}$, online questionnaires ${ }^{104,138,157,168,169}$, unspecified or mixed mode questionnaire administration ${ }^{160-}$ ${ }^{162}$, or a life history writing exercise ${ }^{163}$. Five studies (four of which were primarily based on geo-coded data and one of which was primarily a self-report study) used elements of both the objective and self-report approaches to assess experience/exposure. Importantly, among the studies that assessed experience solely by way of self-reports, only five asked participants to report their experience of climate change manifestations or impacts, while the remaining 14 studies obtained self-reports of extreme weather events (especially, flooding). 
Correlates of climate change, weather, or related experiences included beliefs in/acceptance of the reality of climate change, attributions as to the causes of climate change, risk perceptions/concerns over likely climate change impacts, and climate change policy endorsement.

\section{Evaluation of the Studies}

All 36 reviewed studies have strengths. In many, if not most studies, important issues were investigated, sampling was at least adequate, and approaches to analysis were appropriate. That said, all studies had weaknesses, with strengths of a minority often drawing attention to shortfalls in the majority. Key limitations of this body of research are highlighted below.

As noted, rather than asking participants to report their personal experiences, in 13 studies exposure was inferred from independent sources of weather, hazard, or similar information, with individuals grouped into geographically-defined, and presumably, meteorologically-homogenous, clusters. This approach captures the impacts of weather and environmental events at the regional, rather than individual, level. It thus addresses questions pertaining to weather/climate exposure, rather than questions pertaining to (subjective) climate change experiences. The approach potentially has operational strengths - most notably, the objectivity of its measures and its capacity to circumvent problems associated with participant response bias (see below). Limitations include the questionable validity of some approaches taken to identify geographical regions and/or assess extreme weather/natural disaster exposure.

Nearly all studies used self-report techniques, if not to assess experience, then at least to assess the correlates of experience. Self-reports are prone to two main sources of error: participants may misperceive reality (e.g., they may observe that temperatures are rising when in fact they are not), and they may misreport that which they perceive. The latter is often attributed not to intentional dishonesty, but to memory lapses and response biases including social desirability, acquiescence, and consistency/confirmation biases. Writers in this field (e.g., ${ }^{2,5,24}$ ) have drawn particular attention to the likelihood that self-reports of personal experience may be influenced by pre-existing beliefs or worldviews, coupled with respondent desires to insure consistency between their prior beliefs and reported experiences. Elsewhere in this paper, we argue that neither consistency and confirmation biases, nor 'motivated reasoning', invalidates self-reports of experience or related risk perceptions.

Notwithstanding our observation that many studies operationalized experience of climate change in terms of self-reported experience of (extreme) weather events, we argue 
below that experiences of extreme weather cannot be equated with experiences of climate change. Various other potential limitations of this group of studies were identified: a failure to specify suitable time-frames or geographical locations for the experiences, the dubious practice of operationalising 'experience' in terms of injury or (financial or property) damage incurred, the lack of opportunity provided for research participants to elaborate on their responses, the use of untested, unreliable and/or single-item questionnaire 'measures', the lack of attention paid to indirect experiences, and the occasional inclusion of experiences of other individuals within putative measures of personal experience

In this set of 36 studies, for understandable reasons, true experiments are rare, meaning that causal conclusions could not be confidently drawn. Coming closest to this ideal, the two studies comparing groups of flood affected and non-affected individuals/areas could arguably be termed natural (but not true) experiments. Few studies used longitudinal research designs, with those of Gustafson et al. ${ }^{164}$, Carlton et al. ${ }^{127}$, Konisky et al. ${ }^{125}$, Lang and Ryder ${ }^{140}$, Palm et al. ${ }^{24}$, and Sisco et al. ${ }^{146}$ seemingly providing the strongest evidence of temporal ordering.

In terms of approaches to data analysis, some online surveys reported only univariate findings, while other studies reported mainly bivariate effects. Findings in most studies were strengthened by statistically controlling for demographic, belief/ideological, and other potentially confounding variables. However, few studies examined mediation and/or moderation effects, and even fewer assessed non-linear or multi-level (individuals nested within regions) effects.

\section{Major Findings from the Studies}

Findings from this set of post-2014 studies can be summarized in three parts.

Objectively Assessed Exposure to (Extreme) Weather Events/Conditions/Trends. As noted, 13 studies mainly used geo-mapping or similar techniques to identify regional and hence, by implication, resident exposure to (extreme) weather (events). Most of these studies used survey methods to examine the climate change-related correlates of this exposure. In general, this body of research shows that exposure (to local weather, natural disasters, or multiple extreme weather types) is positively, but not strongly, associated with climate change beliefs, risk perceptions, concerns, issue engagement, policy endorsement, and related outcomes. The obtained effects varied with attributes of the weather to which participants were exposed, although there was limited between-study consistency in this respect. In several studies (e.g., ${ }^{141}, 142,145$ ), the effects of (extreme) weather exposure were small in comparison to those of pre-existing climate change beliefs, political ideology, and 
demographic characteristics. Consistent with most studies in this group, Ray et al. ${ }^{136}$ concluded that the effect of objectively-measured exposure to extreme weather events is "modest, inconsistent across specific adaptation policies, and diminishes with time" (p. 104).

Self-reported Experience of Extreme Weather Events/Conditions. Findings from this group of studies regarding impacts of exposure/experience were similar to those from the previous (objective exposure) category. Self-reported experience of flooding was shown to be associated with heightened climate change concern and risk perceptions 1, 2, 45, 150, 155, 161, preparedness to reduce energy use ${ }^{149}$, increased climate change emotional responses and issue salience ${ }^{2,161}$, and non-flooding adaptation intentions ${ }^{2}$. Zaval et al. ${ }^{162}$ found that present temperature abnormalities were associated with increasing levels of climate change belief and concern. However, many studies 127, 139, 141 154, 156, 165 did not demonstrate clear links between self-reported experiences of extreme weather or disaster events and climate change-related outcomes, and/or did not demonstrate links that were consistent across different types of experiences or climate change outcomes. Several of the obtained effects were mediated and/or moderated by other factors. As is the case for objectively-assessed weather indices, political orientation and prior climate change beliefs tended to overshadow weather experiences in predicting climate change-related beliefs and behaviors.

Self-reported Experiences of Climate Change Manifestation and Impacts. This category of research studies was the focus of our 2014 review ${ }^{6}$, when we identified only four studies in this category. Somewhat surprisingly, research with this focus is still quite rare, with only five of the present set of 36 studies directly operationalizing 'personal experience' of events, conditions and/or changes that respondents perceived to be manifestations of global climate change. Three of the five studies reported the percentage of their respondents who claimed to have had direct personal experiences of climate change, its manifestations, or impacts. These studies and the associated percentages of respondents were: Babutsidze et al. ${ }^{157}$ : 55\% ; Capstick et al. ${ }^{103}: 76 \%$; Leiserowitz et al. ${ }^{104}: 46 \%$, Discrepancies in these figures presumably reflect differences in study setting, timing, sampling, question wording, questionnaire context, and other factors. In general, these 2014-2019 estimates of the population prevalence of climate change experiences are higher than are estimates obtained in previous years ${ }^{6}$. Studies in this group seldom reported tests of the associations between experiences of climate change and related beliefs, attitudes, or behaviors. An exception is Broomell et al. ${ }^{138}$ who found that climate change experience was more strongly associated with willingness to engage in specific mitigation acts than with general intentions to act. The relative neglect of the correlates of direct personal experience in this set of five studies stands 
in contrast to the four studies reviewed in $2014^{6}$, in which a range of cognitive (e.g., belief certainty, risk perception) and behavioral correlates were investigated.

Summary of the Findings. Based on our reading and assessment of this arguably representative selection of recent studies of this topic, we offer the following three propositions as a summary of the findings:

1. The majority of recent studies have relied on either objective evidence of exposure to extreme weather or natural disasters, and/or self-report evidence of these experiences. These studies have yielded mixed, seldom strong, and often qualified, evidence of associations between exposure to/experience of these events and climate change related beliefs, attitudes, and behaviors, with most research suggesting that these outcomes are better predicted by pre-existing political, environmental, and ideological values and beliefs.

2. Few recent studies have obtained self-reports of personal experiences of climate change. From the research that has been conducted, it seems that the incidence of perceived direct climate change experiences has increased in recent years, but limited evidence has recently been published as to the antecedents, significance, or issue engagement influence of these experiences.

3. The effects of experience may ultimately be found to be indirect, conditional, and nonlinear, but until the conceptual, measurement, methodological, and analytic shortcomings of the recent research are addressed, clear conclusions will continue to be elusive.

\section{DISCUSSION}

When addressing such topics as environmental risk perceptions, understandings, or personal experience of climate change, language and meanings matter, and terms and construct specification and clarity particularly matter, whether communicating with research respondents, the public, policy makers, or fellow scientists. When the subject being discussed or researched encompasses global phenomena, issues, and implications, these matters become even more critical. This has all been challenging in the context of global climate change, a grave global threat, a very salient environmental stressor, a complex phenomenon requiring the expertise of very different areas of the biophysical sciences, the social and behavioral sciences, and the humanities - all contextualized within often very different assumptive worlds, involving differing research and problem approaches, and respective languages and argument and evidence-based criteria. 
In the context of this review, an important focus and challenge has been the language used when referring to global climate change, experience, exposure, significance, and influence, and the cross-disciplinary translation and operationalization of these external and internal environmental processes, considerations, constructs, and parameters in the research examined. Clearly global climate change involves two very different formal definitions and a spectrum of public understandings. In our review we have acknowledged these differences, but have subscribed to the Kyoto Protocol specification of anthropogenic climate, in large part because this both corresponds to what is arguably everyday use and meaning, and because this matters greatly with respect to the nature of the hybrid environmental risk domain and environmental stressor status of climate change.

A further challenge has been the nature and meaning of experience, and in particular perceived personal experience of environmental changes, conditions, or events deemed to be probable manifestations of climate change. Any encompassing consideration of the human dimensions of climate change can founder on what such individual and collective experience encompasses. The research focus we have addressed narrows the compass of the challenge to a considerable extent as we are dealing with individual level, natural environment contexts, perceptions, encounters, and experiences, and more specifically the nature and extent, and the psychological significance, and issue engagement influence, of such perceived environmental encounters. While researchers addressing the personal experience of climate change are largely aware of many of these considerations, they have not been very clear about how and why they have framed their research questions or devised their research methods, procedures, operationalizations, and 'measures' as they have, nor have they often situated their research with respect to this broader multidisciplinary space, or their own disciplinary perspectives and assumptions. This, in our view, has led to considerable confusion about what was actually being researched, what these research findings, overall, might suggest, what conclusions might be drawn and communicated to policy makers and government bodies addressing the immense challenges of unfolding climate change, and what corrective research and public risk communication and issue-engagement measures might be undertaken. In the discussion which follows we examine a number of these overarching issues in the context of the research studies we have considered.

\section{What is 'experience' and what is its status?}

It is interesting and instructive that the primary and secondary definitions of 'experience' in the Oxford English Dictionary are "a procedure carried out to test or demonstrate something: an experiment" and "proof by actual trial: practical demonstration". The tertiary 
definitions of 'experience' are "actual observation of or practical acquaintance with facts or events, considered as a source of knowledge" and "a state, condition, or event that consciously affects one; the fact or process of being so affected." A further definition in this source is "knowledge resulting from actual observation or from practical acquaintance or from what one has undergone" $\left({ }^{166, \text { p. }}{ }^{894}\right)$.

Experience is without question an encompassing term and expression. Clearly 'everyone knows' at some levels what 'experience' means and covers, but its etymology, history, use, and meanings in philosophy and the human sciences underscore the polysemous nature of this vital term and multileveled construct. It is worrying that throughout this past decade of social and behavioral science research addressing the nature, significance, and influence of personal experience of climate change, the fundamental meanings and empirical status of perceived and subjective 'experience' would appear to have been largely ignored or dismissed. This unfortunately reflects the multidisciplinary character of the research, preferred levels of analysis, and a physical science 'positivism' that finds expression in a strong focus on the physical, the 'objective', the observable and measurable. This is so despite a firm conviction that "One thing which all sciences show in common is an insistence that in the last analysis they are founded upon human experience.” $\left({ }^{167}\right.$, p. 520 $)$. Indeed, empiricism itself is defined by many in terms of experience.

In all its forms, empiricism stresses the fundamental role of experience. As a doctrine in epistemology it holds that all knowledge is ultimately based on experience. $\left({ }^{168, p p}\right.$. $\left.{ }^{239-240}\right)$.

There are clearly multiple language and meaning issues when discussing or researching personal experience of climate change. 'Personal' or 'individual' implies an individual level of analysis and an arguable need for some level of self-report. While one can collect and/or examine locational data relating to individual residence and extreme weather events or environmental changes, and infer exposure, this is a considerable remove from direct selfreport of personal encounters with and experience of perceived manifestations of global climate change. Similarly, 'experience' can be viewed and defined from an observer or analytic perspective as an incident, occurrence, or event, but this is not what is generally inferred or implied when discussing the nature, significance, or influence of direct, personal experience. This distinction reflects both differing levels of analysis and the substantive nature of individual level, subjective, personal experience, particularly when researching the nature of what occurred and was perceived and experienced from the respondent's vantage point. One must approach the definition and specification of global climate change from the 
respondent's perspective, as well as conceptually and operationally. This circumstance takes as read that the environmental change, condition, or event encountered and made sense of as a probable manifestation of climate change encompasses one's environmental risk perception, internal experience, and individual-setting 'transaction' with this circumstance, in the broader context of whatever activity one has been involved in. It would be very difficult to ascertain or examine almost any aspects of individuals' personal experiences of perceived manifestations of climate change without obtaining individual level accounts of the incident or situation and individuals' perceptions and subjective experience in and of this situation.

Whether one takes an environmental perception perspective, an environmental risk perception perspective, an environmental psychology transactional perspective, a causal attribution perspective, or a sense-making perspective (e.g., ${ }^{56,58,59,72,169-172}$ ), an individual's perceived personal encounter with and experience of an environmental change, condition or event perceived to be a probable manifestation or consequence of global climate change is an important psychological reality. This is so irrespective of whether IPCC atmospheric or biophysical scientists would judge such an environmental change, condition, or event to have been caused or otherwise influenced by anthropogenic global climate change. Indeed, many such scientists would confirm that in the current context virtually all weather events are influenced to some extent by global climate change (e.g., ${ }^{100}$ ). It is also useful to appreciate that from an 'objective', environmental psychological or environmental perception perspective what is being considered is an individual encounter and transaction with an anomalous or noteworthy aspect of a natural environment (e.g., ${ }^{173-175}$ ). The 'personal experience' of this encompassing transactional encounter in the context of responding to a survey or interview question, concerning the recalled encounter and experience - further nuanced by one's intervening reflections, possible conversations, and information-seeking about such an experience - are all important considerations.

Standing back from such considerations, it is remarkable that many researchers would intentionally exclude self-reports of research respondents' encounters with and experience of perceived climate change manifestations or consequences. The expressed rationale for such procedures is typically that this ensures that factors such as motivated reasoning, confirmation bias, protection motivation, and a spectrum of other 'subjective' and heuristic 'biases' do not detract from a credible research focus on the 'objective' influence of an empirically confirmed environmental event on 'objectively measured' behavioral responses (e.g., ${ }^{2}$ ). However, such procedures unfortunately disregard the very nature of environmental perceptions, the noun and verb status of experience, the inherent subjective nature of 
experience and experiencing, and the nature and cognitive, affective, and symbolic meanings of an environmental risk domain such as anthropogenic climate change (e.g., ${ }^{58,95,176}$ ). Such procedures also preclude the possible psychological significance and personal importance of such an experience, and the nature of subsequent psychological adaptation and issue engagement responses to the experience that are not overtly behavioral.

The centrality and human dimensions of experience are universally accepted in psychology, philosophy, literature, and the arts and humanities generally (e.g., $62 ; 177-182$ ), but so unquestioningly accepted that the importance of experience across many behavioral science research domains has been, paradoxically, both taken for granted and/or intentionally set aside, as it has in more 'behavioral' psychological research, or in social science disciplines in which individual or experiential levels of analyses are exceptional rather than mainstream. This is not to suggest that one's disciplinary vantage point necessarily precludes more 'psychological', 'internal environment' considerations. Phenomenological geography perspectives, for example, have made crucial contributions to understanding the human dimensions of climate change (e.g., ${ }^{3,55,159,183-185}$ ).

Why might perceived personal experience of climate change be particularly salient and psychologically significant?

One might well argue that those spending time in natural settings often have salient and out-of-the-ordinary environmental encounters. But personal environmental encounters with the perceived consequences of climate change, particularly initial such experiences, are arguably quite different. Such encounters are typically with respect to unusual environmental changes or incidents, often by way of deteriorating or otherwise alarming circumstance or changes in one's own familiar setting, and possibly reflecting a particular mindfulness, and felt connection with one's familiar natural environment. Such perceived climate change influences and consequences are by definition anthropogenic or human-forced, underscoring both human agency and impacts and accompanying associations, including the stigma and consequences of a societal or science/technology-based 'tampering with nature' (e.g., ${ }^{96,101}$ ). Others have written about such experiences as a 'bringing of climate change home' (e.g., ${ }^{3}$, ${ }^{61}$ ), whether by chance encounter, or in the context of genuinely appreciating, and realizing, what global climate change means and portends in one's known home environment. This itself can be a powerful and personal 'witnessing' of this altering 'state of the planetary environment'. It is also likely that such personal encounters make one's virtual exposure to and experience of global climate change more real, immediate, and disturbing. The thoughts and emotions that can accompany such personal experience can range from concern, to 
apprehension, to anger, to guilt, to felt helplessness, to loss (e.g., ${ }^{25,26,186-189}$ ). There can also be countering emotions and motivations relating to confirmation, realisation and resolve with respect to what has been a disputed and seemingly distant, temporally and geographically, phenomenon and threat.

The grave risk of climate change, its ubiquitous media coverage, its environmental stressor character, and perceived impacts in one's own immediate natural environment, all make a personal encounter with a perceived, probable, manifestation of climate change very salient and psychologically significant for many individuals. This psychological significance is in many ways as important as environmental significance (e.g., ${ }^{190,191}$ ), and arguably a sine qua non for both issue engagement and psychological adaptation as well as behavioral change

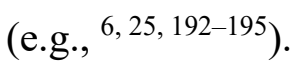

\section{Sense-making, causal attribution, and survey questions and response options}

Clearly, individuals' perceived personal experience with environmental changes or incidents which they deem to be likely manifestations of climate change (PPEOCC) reflect some form of causal attribution and sense-making, and de facto environmental risk perception ${ }^{100,133}$. This personal meaning-making in the context of transacting with one's natural environment is, again, quite different from the scientific detection and attribution of noteworthy environmental changes or extreme events (e.g., ${ }^{100,196,197}$ ). The question of whether climate change scientists would regard the environmental change, condition, or event as attributable to global climate change is again irrelevant to the question of the nature and psychological significance and influence of such perceived and experienced encounters on the part of an individual. Hence it is important to distinguish between these two very different circumstances, that of a science-based 'expert' judgment and causal attribution assessment, and that of an individual's encounter with an environmental event or condition perceived by she/he/group to be a likely consequence of climate change. Yet much of the research which has been addressing the nature and role of 'personal experience' in the context of climate change has taken a research design stance in which extreme environmental events, not necessarily linked to global climate change, are linked to 'geocoded' residence and a locational risk analysis of survey respondents (e.g., ${ }^{123}, 198,199$ ), without reference to, and typically in the absence of, individual reports or informative first-hand accounts of personal experience with environmental events or conditions which respondents deemed to be probable manifestations of climate change. Alternatively, in other 'experience of climate change' research contexts, extreme weather events and natural disasters are simply and 
routinely treated as concrete and credible proxies for climate change (e.g., 2, 125, 136, 149, 150, 152, $160,200)$.

The problematic equating of extreme weather events and their impacts with global climate change

An extreme weather event, or extreme weather generally, arguably does not equate with or serve as an acceptable proxy for global, anthropogenic, climate change, a human-forced alteration of planetary atmospheric systems and global weather and climate regimes, and its myriad and devastating ecosystem and human life and societal system impacts. What is central to the nature, significance, and influence of direct personal experience of an extreme weather event in the context of climate change is whether research respondents' personal experience and environmental risk perceptions and attributions are such that the event is perceived and experienced as a probable manifestation of climate change (e.g., ${ }^{6,102,103}$ ). Yet in most of the reported research presented as addressing the salience and influence of perceived encounters with climate change-related events, neither the methodology nor the data include or report on individual accounts or responses or reflections, by way of open survey response options or similar interview prompts for expanding a response. Research respondents are seldom directly asked whether they have ever directly experienced an environmental change, condition, or event which they deemed to be a probable manifestation or consequence of climate change (e.g., ${ }^{4}$ ). Indeed, in the present sample of articles reviewed, only five of 36 studies included such an item in their survey, interview, or other data collection procedure.

The counter-argument which has been more recently made is that individual level reports/accounts of personal experience of environmental changes, condition, or events are prone to multiple biases (e.g., motivated reasoning, the availability heuristic, memory accuracy) and an absence of objective evidence. In contrast (this argument goes), personal reporting of documented extreme weather event effects and their material impacts, such as damage due to flooding, are far more reliable and empirically credible and defensible than individuals' environmental perceptions and sense-making with respect to reported environmental encounters (e.g., ${ }^{2,4,103}$ ). What again is missed in such arguments and accompanying methods is that the subject matter and focus of either stated or implicit central importance, i.e., the interrelated environmental risk perceptions, understandings, sensemaking, and related internal and external psychological processes, responses, and impacts of an attributed climate change event, are neither really addressed or assessed, other than in rare instances, by post event interviews related to a severe flooding event. This is in a context in 
which everything is really about the natural disaster event, and physical and often financial impacts, during which matters of climate change attribution and concerns are raised. In contrast, in a survey or interview about possible personal encounters with perceived climate change manifestations or consequences, the context and questions are much more directly about this experience itself, with survey or interview items relating to attribution, concern, distress, issue engagement, commitment, and pro-environmental lifestyle changes.

It has been compellingly argued and increasingly evidenced that climate change is a dramatically unfolding existential risk, both objectively and subjectively, for ecosystems, biodiversity, and human societies, and a rapidly altering planetary condition that may well be with us for millennia ${ }^{201,202}$. Specific extreme weather events are, in contrast, time and region specific, and natural and known phenomena, with century and millennial old culturally informed adaptation wisdom, and however damaging and devastating, are part and parcel of the landscapes and lives of all countries and cultures (e.g., ${ }^{203,204}$ ). Australia, 'land of drought and flooding rain' 205 , is arguably the most currently exposed inhabited continent to the ravages of climate change. The present authors' own Australian research program ${ }^{26,206}$, mandated to address public risk perceptions, understandings, and responses to both extreme weather events and global climate change, found that the psychological significance and influence of reported direct extreme weather event/condition experiences were remarkably modest when compared with reported, perceived, direct experience of environmental changes, conditions, and events attributed to climate chance 26, 206, 207.

Perhaps the strongest argument against the use of extreme weather events as documented, empirical events and conditions representing climate change is that considerable convergent, cumulative, research evidence indicates that the contribution of assumed or established personal experience of extreme weather events to acceptance of, issue engagement with, or overt behavioral influence relating to climate change is very modest, with this finding and conclusion being stated in many of the research reports reviewed in the online supplemental materials and elsewhere (e.g., ${ }^{4,47,115,116,124,125,127,133,135,138,158,160,161,208-215}$ ). These findings throw into serious question the current methodologies and wisdom of approaching the nature, significance and influence of personal experience of climate change through the examination of geo-referenced exposure to or more directly assessed personal experience of extreme weather events, not assessed as attributed to global climate change by survey respondents at the time of their occurrence.

This is not to suggest that the human dimensions and impacts of natural disaster events are not very powerful and often devastating (e.g., ${ }^{216-219}$ ). But such experience has historically 
and culturally been largely attributed to natural causation. Indeed, other than in some traditional subsistence cultures, all countries and cultures make sense of and come to terms with naturally occurring extreme weather events and 'natural' disasters in culturally congruent and adaptive ways, with culture itself being a formidable adaptation process and agent (e.g., 177, 178, 220, 221 ). However, and again cross-culturally, when dramatic, exceptional, and out-of-historical-context environmental events and conditions appear, such phenomena can constitute very different and troubling environmental risk domains and narratives (e.g., ${ }^{73}$, $203,221)$. The 'story of climate change' itself has become a powerful, global, narrative, nuanced by regions and cultures and social representations, and interwoven with differing takes on adaptation and mitigation responsibilities and possibilities (e.g., ${ }^{222-226}$ ).

It is extraordinary that 'social and behavioral science' based climate change research over the past decade which has been expressly addressing the nature and putative significance and issue engagement influence of personal experience of climate change would intentionally, 'strategically', and operationally not seek, or examine the actual perceptions, experiences, understandings and responses of individual research participants. This is despite the pressing need and call for more basic, primary, research on the more qualitative, phenomenological, psychological, nature of such perceptions, experience, impacts, and 'human dimensions' of climate change $\left({ }^{8,182,189}\right)$. Similarly, there would appear to be limited appreciation that adaptation, a fundamental construct within psychology for well over a century (e.g., ${ }^{71,194,227,}$ ${ }^{228}$ ), encompasses a fundamental suite of internal environment emotional and cognitive processes arguably integral to individuals' coming to terms with/adjusting to the stark and escalating threat and challenges of climate change (e.g., ${ }^{25,229}$ ).

\section{Virtual and vicarious exposure and experience}

The 'new media' information environment is a very real, ubiquitous, immersive, 'environment' taking up a dramatically increasing amount of experiential engagement and time globally. Extensive Pew Research Center findings provide compelling U.S. statistics. "As smartphones and other mobile devices have become more widespread, 26\% of American adults now report that they go online "almost constantly", up from $21 \%$ in 2015, according to a Pew Research Center survey conducted in January 2018. Overall $77 \%$ of Americans go online on a daily basis." 230

One need only look at 'where the public is at' when walking down the street or taking any form of mass transit, in most countries in the world, with an expert assessment in 2014 finding that people around the world spend an average of 485 minutes a day consuming media $^{231}$. From a 'virtual' natural environment experience perspective this new 'reality' 
clearly needs to be taken into account. Such media coverage reflects and is accompanied by the image-focussed 'landscape' of climate change-themed commercial films, documentaries, and YouTube vignettes (e.g., ${ }^{232}$ ). Paradoxically, this itself makes direct personal experience of perceived climate change manifestations in known natural environments even more arresting and alarming, conferring 'reality' and catalysing realisation - and, for many, resolve - concerning this clearly global but increasingly 'backyard' and alarming environmental threat and unfolding reality ${ }^{6,45}$.

It is very likely the case that initial personal encounters with perceived manifestations of climate change have been preceded by considerable exposure to and vicarious experience of climate change through extensive multi-media and other popular culture coverage. There would be few individuals in internet-connected modern societies who have not had such exposure. This foreshadowing of a person's initial encounter(s) with perceived local manifestations of climate change can make climate change very real and proximate in a powerful way for many. A plausible reason for this might be that such first-hand experience can validate and confer reality to a global phenomenon, risk, and change which has been virtually communicated, contested, extensively media-portrayed and covered, and a background source of unease, and for many felt distress. This is not to dismiss the probable and simultaneous psychological reality that concerned individuals might be particularly 'attentive', when in natural settings, to the state of their known natural environment, and whether there might be local evidence of global climate change. But this is arguably a far cry from the motivated reasoning, 'believing is seeing', counter explanations for quite genuine perceived personal encounters with 'climate change', and the accompanying psychological significance and influence of such experiences (e.g., ${ }^{49,233}$ ). A parallel dynamic occurring in the context of such personal encounters is that such experiences become an integral part of psychological adaptation processes, the 'coming to terms with' the reality and reach of this global alteration and risk domain, and what it means and portends (e.g., ${ }^{6,25}$ ). Such enhanced validation, acceptance, and realisation is likely an ubiquitous aspect of climate change adaptation occurring across the world, yet does not seem to be on the radar of climate change science or policy consideration and formulation.

\section{The matter of psychological distance}

An argument which continues to be made, across disciplines, is that of the 'psychological distance' of global climate change, emphasizing geographic and temporal 'distance' considerations, uncertainty and social distance, phenomenon and issue global scale and complexity, and convergent protection motivation responses to a salient and grave threat 
(e.g., ${ }^{28,31,234-240}$ ). In a somewhat different vein, a number of authors and researchers argue that it makes little sense to speak of individuals' experiencing 'climate change', given the global, atmospheric system, wicked problem nature of climate change, its largely future threat status, and the inability of any individual to accurately ascertain causal attribution of any specific environmental event or condition (e.g., ${ }^{241}$ ). Clearly these arguments are relevant to the issue of direct, personal experience of climate change, although they lose some currency given that this latter consideration and focus is a matter of environmental perceptions and sense-making, and given the affect heuristic relevance of the climate change risk domain (e.g., ${ }^{59}$ ).

While it is self-evident that the physical science-based nature and scope of climate change is intrinsically difficult to understand ${ }^{28,242}$, and indeed a worrying and ongoing environmental stressor ${ }^{130,243}$, the aspects of climate change which can certainly elicit psychological defense mechanisms, also reflect the pervasive salience and 'presence' of climate change, ensuring that it is not 'out of mind'. While the cases for both the power and the limitations of personal experience in understanding climate change can be persuasively made (e.g., ${ }^{242}$ ), an individual's sense-making and environmental risk perceptions in the case of personally encountering an anomalous environmental change or condition are both hard-wired by biological history and sensitized by the 'availability' of ongoing and extensive media coverage of global climate change ${ }^{244-246}$. And while there is no question that the profound risk of global climate change can initiate understandable and extensivelyresearched 'protection motivation' mechanisms (e.g., ${ }^{118,247}$ ), and the reality that global climate change constitutes a formidable convergence of complex issues, this general psychological distance argument is very much at odds with the ubiquitous multimedia coverage of climate change, the very high percentages of reported direct personal experience of perceived 'climate change' related environmental encounters, and the visibility and availability of climate change in social representations, popular culture, and everyday conversations. The current global extinction rebellion, as a social movement, social representation, and collective response, is a compelling case in point.

The sheer quantum of virtual, vicarious, and direct personal exposure and experience and indeed the increasingly dramatic unfolding of global climate change environmental impacts across the planet - does render the nature and level of the psychological distance argument rather moot. Thorough review of research addressing the nature, dynamics, and influence of putative psychological distance, and the effectiveness of countering 'proximizing' strategies, would strongly suggest that such psychological distance in the 
context of climate change is far less pervasive than theoretical arguments might indicate, and that when and where it might exist, it may well have very modest influence on either issue engagement or behavior change.

\section{Issue engagement and behavior change: psychological significance and environmental significance}

Considerable confusion exists with respect to the language and terms being used when addressing climate change communication, issue engagement, and behavior and lifestyle change in the context of climate change. The nature of personal experience, and the roles it might play are clearly seen as important research foci. Two particularly frequent terms which permeate this communication and persuasion aspect of the human dimensions of climate change are 'environmentally significant' behavior change and 'issue engagement' when speaking of fostering or promoting pro-environmental behavior. Environmental significance, in the contexts of promoting pro-environmental behavior and climate change adaptation, refers to decisions and overt behavioral actions which result in materially reduced individuals' or households' carbon footprints (e.g., ${ }^{191,248,249}$ ). The phrase also has specific meaning in environmental protection legislation around the world relating to substantive environmental impact(s). In the United States this requires that "a person who proposes to take an action that will have, or is likely to have, a significant impact on a matter or environmental significance must refer the action to the minister for a decision as to whether assessment and approval is required by the EPBC Act" ${ }^{85}$. This 'environmental significance' is an expression which, in everyday discussion, is used to clarify and emphasize that environmental issue engagement has 'real', consequent, outcomes and dividends for the natural environment, whether in terms of environmental conservation, restoration, or protection. However, in environmental social science this expression has taken on a more specific 'behavioral' and 'scientifically measurable' meaning with respect to 'making a difference', and is effectively code for quantifiable or otherwise empirically demonstrable behavior change or altered environmental impact.

Unfortunately, this more formal 'evidence-based' meaning has become de rigueur in the environmental sustainability and climate change sciences generally, associated with acceptable evidence 'confidence levels' (e.g., ${ }^{201,250,251}$ ) for credible reporting, while the more encompassing meanings of personal importance and psychological significance have been largely ignored, as have more 'psychological', evidence-based, research criteria generally (e.g., ${ }^{252}$ ). Much research addressing the significance of exposure to or experience of extreme weather events, for example, has used a 'scientific' and very behavioral and 
'behaviorist' gloss of this phrase, again excluding the relevance of personal importance or meaningfulness connected to a reaction or response to an environmental issue or concern, or issue engagement which is largely internal, motivational, and psychological. This language and meaning issue is rather crucial in the context of personal experience of perceived climate change, as demonstrable empirical evidence is the sole evidential criterion for much research in this area. This is so despite the public engagement objective of much social science climate change research being enhanced awareness, changed understandings, and personal issue engagement, which can encompass much more than overt behavioral actions or change. The research that we have examined in this review has reflected some exceptionally strong views on what would and would not be considered credible research when addressing personal experience of perceived climate change, again with self-report of one's own environmental encounters, environmental perceptions, sense-making, and personal responses seemingly viewed as too prone to subjective bias, heuristics, and memory lapses to be considered as credible data or evidence.

\section{Challenges in documenting psychologically significant and influential} environmental risk perceptions and personal experiences through current research strategies

The problems and challenges of research addressing public risk perceptions, understandings and responses to climate change are many (e.g., ${ }^{26,33,115,163,193,206}$ ). They include credible sampling, mode of administration, time constraints, longitudinal research challenges including continuing research programs and funding, respondent identification, attrition, credible and standardized items and scales, capturing qualitative accounts, etc. The need for longitudinal monitoring and documentation of change and impacts, and the often necessary use of panel survey service providers for cost and administrative reasons, has led to the widespread use of questionnaire-based surveys as the predominant research strategy when individual respondents and their views are desired or required (e.g., ${ }^{1,253}$ ). However the nature of this ongoing, global, phenomenon of climate change, and its dramatic, unfolding, environmental changes and impacts, clearly require strategic and ideally longitudinal research monitoring programs, and survey items and response options that provide credible measures of individual level environmental perceptions, understandings, and responses. Where closedended questions are used, a standard set of items is needed to permit valid comparisons across studies, times, and nations. There is also a crucial need to supplement such research platforms and programs with parallel qualitative research with the capacity and sensitivity needed to more adequately ascertain, document, and explore changing individual level 
experience of, responses to, and psychological and broader health and well-being impacts of, climate change $6,8,21,27,163$.

The distillation of objectives and operationalizations of personal experience of climate change in the online supplemental materials clearly illustrate the problems and underlying issues in how researchers from differing disciplines have approached questions pertaining to the nature, extent, and influence of personal experience 'of climate change', with extreme weather events, conditions, or consequences serving as a presumed, de facto, face of climate change. Many of these studies do not investigate self-reported, perceived, personal experience of natural environmental changes, conditions, and events deemed to be probable manifestations of global climate. As noted, only five of the reviewed studies involved the presentation of one or more transparent question(s), whether by survey or face-to-face interview, to individual respondents about whether they might have had such an experience, and, if so, the nature and significance, and self-reported influence, of this perceived climate change experience/encounter. In many ways the statements of purpose and methodology employed in these studies tell us more than the reported findings do about what can be concluded regarding respondents' personal experience of climate change. We are presented in these research articles with very different constructions and operationalizations of personal experience, along with an effective dismissal of the validity and value of environmental risk perceptions, psychological significance and impacts, and psychological adaptation and issue engagement responses - as contrasted with possible but very problematically 'measured' environmentally significant overt behavioral responses. Researchers need to identify individual and contextual variables that moderate the effects of self-reported personal experience, and they need to examine possible nonlinear, reciprocal, and multi-level effects of experience on diverse internal, individual, and collective states and processes.

\section{Concluding commentary}

What observations can be made, and/or conclusions drawn, from this very diverse picture of research objectives, assumptions, methods, and operationalizations? There is no doubt that research on personal experience is both important and strategic. While the authors' 2014 review identified few relevant articles, this current, broader, review identified and considered 36 articles of comparable relevance. In the context of their own research, other authors have also reviewed research findings addressing the nature, extent, and influence of 'personal experience of climate change' (e.g., 1, 7, 113, 126, 133, 212, 235, 254). A paradigmatic example of issues addressed in these reviews has been that of 'seeing' versus 'believing' in explaining research findings relating to the nature and role of personal experience of climate change 
(e.g., ${ }^{5,6,47}$ ). A parallel rationale has been that a better understanding of climate change experience might well provide needed insight into not only how such knowledge of personal experience can be strategically used (e.g. ${ }^{255}$ ), but, equally importantly, how these 'internal environment' processes are mediating and moderating both successful psychological and behavioral adaptation, and the psychological, social, and environmental impacts of climate change (e.g., $\left.{ }^{130,243}\right)$..

What becomes very apparent in reviewing this research landscape is what is largely absent. Missing elements include:

- a common, cross-disciplinary, climate change research-specific, language for those working in this arena;

- a standardized glossary of core terms, constructs, and research methodology and procedure-reporting terminology;

- an accurate and encompassing gloss of experience in the context of climate change, reflecting perspectives of both the humanities and the social and behavioral sciences, which identifies and differentiates the multiple ways in which personal experience of climate change has been operationalized in this research area, and what is lost and gained in each such operationalization;

- an addressing of and clear differentiation between exposure and experience, and direct personal experience and virtual and vicarious experience, in the context of the research being reported;

- a common understanding and appreciation of differing disciplinary research approaches and assumptions, and their respective advantages and disadvantages, when addressing subjects such as environmental risk perception and personal experience of perceived climate change;

- a more informed knowledge and appreciation of the research undertaken across the social and behavioral sciences over the past several decades relevant to the nature and putative psychological significance, and issue-engagement influence, of perceived personal experience of climate change;

- a situating by authors of where and how their research sits within this emergent field of research, and with respect to what is common to and what differs from previously published research. 
- an acknowledgement of the philosophical, conceptual, and methodological issues involved, and how these were addressed and navigated in the research undertaken and being reported.

An addressing of these missing elements would give readers and fellow researchers confidence that the studies undertaken were well-considered and informed by current research and prior reviews.

As discussed, a further and embedded matter relating to the scientific status of constructs, theories, methods and 'evidence' looms large in the context of climate change research and IPCC/USGCRP criteria relating to 'confidence' in findings. Scientific status and relevant assumptive world issues also continue to reflect the strong 'behavioral' focus of the work of many researchers working in areas of environmental social science, with the promotion of environmentally significant behavior change being a principal target ${ }^{192,256}$. But the nature and more challenging status of 'internal environment' psychological processes relating to cognitive, emotional, adaptive, and motivational processes, and constructs such as personal importance, psychological significance, concern, self-efficacy, and psychological impacts generally, have tended to have lesser status and climate change science credibility, with research findings relating to these constructs and processes rarely meeting natural and physical climate change science 'confidence' criteria, for example in IPCC and USGCRP scientific assessment reports (e.g., ${ }^{250,257}$ ).

While all of the studies examined have individual strengths, and together provide an increasingly detailed picture of some specific kinds of climate change-related 'experience', the selection of the events and conditions researched has meant that this emergent picture has many blank but crucial spaces. That flooding events were the single major focus of 11 of the 36 studies reviewed (and one of several foci of a further 15 studies), and the absence of any self-report by individual research respondents characterized the research of a further nine of these studies, is again extraordinary given the ostensible focus of each of these studies on personal experience of climate change. The seeming limited interest in, and in some cases the provided rationales for not examining, individual level accounts, and indeed the phenomenology of such personal experience, are not entirely inexplicable, but are disappointing. Importantly, effects vary with the psychological processes (e.g., appraisals, attributions) and states (e.g., distress, resolve) elicited by the experience, yet these processes and states, as mediating variables, have seldom been adequately studied. This is where more research is most needed. Simply conducting more studies of the relationship between exposure to EWEs/NDs and CC understandings and responses will produce more 
(inconsistent) evidence of weak effects. Such currently favored and widely adopted approaches miss the nature, psychological significance, and issue-engagement influence of personal, perceived, climate change experiences for many, and have certainly not achieved the credible and crucial transdisciplinary understanding that is needed (e.g., ${ }^{8,254,258}$ ).

\section{The research landscape looking forward}

It is arguably helpful and strategic to think through where further research on personal experience of climate change might head. The need for more longitudinal research which can capture individuals' changing encounters and experiences and a transforming natural environment and landscape is a very important component of psychosocial environmental impact assessment (PSIA) and monitoring over the crucial decades facing human communities and their governance. This requires some consensus, other discipline awareness, and where possible and useful, standardized procedures, methods, and measures both within and ideally across disciplines. Clearly, the current research landscape reflects many interdisciplinary and transdisciplinary research studies and reviews, and some heartening signs of ongoing, well-funded, programmatic research platforms and programs. There is of course considerable value in retaining and well-utilising the distinctive disciplinary lenses we bring to the study of the human dimensions of climate change, including the crucial crossvalidation that such convergent research brings. But these social and behavioral science research approaches must also provide a much clearer and coherent research landscape and set of substantive findings to better inform the views of many natural/physical climate change science colleagues and organizations. This might insure a stronger representation of the social sciences and humanities in such bodies, and a fuller appreciation of the findings of the past four decades of research addressing the human dimensions of climate change.

In summary, we recommend the following in the context of further research in this area:

- that researchers who are addressing the nature and context, salience and significance, and issue engagement influence of perceived personal encounters with environmental changes, conditions, or events deemed to be likely manifestations of climate change, clearly state this, along with their specific research focus(i) and objective(s).

- that researchers not directly asking individual respondents whether they have personally encountered or experienced what they perceived to be probable environmental manifestations of climate change clearly state this, explaining why and how their research nonetheless addresses perceived personal experience of probable climate change manifestations. 
- that researchers employing extreme weather events, conditions, or personal, household, or property impacts resulting from extreme weather events, as de facto operationalizations of, or indicators of, 'personal' experience of climate change' clearly explain and support such use;

- that researchers clearly indicate their working specification/definition of climate change [i.e., Kyoto Protocol or IPCC or other definition/specification], and how this use and understanding might pertain to the wording of survey items, or interview questions concerning 'climate change'.

- that researchers also clearly communicate and specify their understanding, definition, and use of 'experience' [or 'personal' or 'direct' experience] and how this experience has been operationalized and examined, clarifying level(s) of analysis;

- that researchers writing for and addressing multidisciplinary audiences state their disciplinary perspective(s) and attempt, where possible, to adopt more standardized language and terminology concerning construct and parameter specification, and operational procedures and measures, allowing for more meaningful comparisons across studies, and enhanced reader understanding and evaluation of stated findings;

- that researchers situate/locate their research with respect to other relevant research approaches and methodologies in this multidisciplinary 'personal experience of climate change' space;

- that researchers more clearly address and explain what can or cannot be concluded from their research findings given their approach, procedures, measures, and analyses, and the limitations thereof.

The current state and speed of already unfolding natural environment and ecosystem system impacts of climate change are such that initial perceived and impactful personal encounters with noteworthy environmental changes, conditions, and events attributed to climate change may be far less frequent and striking moving forward. It might also seem that the dividends of a closer and more informed focus on the nature and significance of individual level experiences of perceived climate change consequences in one's known, familiar natural environment are very real and promising at present, but likely to fade as the world moves past this liminal period in which mitigation and adaptation measures might make a consequential difference to how severe and irreversible this climate change disequilibrium and disruption will be. However this makes it even more imperative that there exist a more informed transdisciplinary and transactional understanding and language for addressing, researching and better utilising 'internal environment' adaptation processes that 
are and will continue to be mediating how individuals come to terms with the ongoing environmental stressor and psychological and societal impacts of global climate change. Such a focus will not displace the need for continued monitoring and risk and impact assessments relating to geographic proximity and exposure to high risk environments in this phase of the Anthropocene, but it will substantially assist in the design of risk communication, adaptation, and issue engagement strategies and policies for what is already shaping up to be the new and very stressful abnormal.

\section{$\underline{\text { References }}$}

1. Borick, C. P., \& Rabe, B. G. (2017). Personal experience, extreme weather events, and perceptions of climate change. In M. Nisbet (Ed.), Oxford research encyclopedia of climate change communication. 1-17. New York, NY: Oxford University Press.

2. Demski, C., Capstick, S., Pidgeon, N., Sposato, R. G., \& Spence, A. (2017). Experience of extreme weather affects climate change mitigation and adaptation responses. Climatic Change, 140, 149-164. doi: 10.1007/s10584-016-1837-4

3. Devine-Wright, P. (2013). Think global, act local? The relevance of place attachments and place identities in a climate-changed world. Global Environmental Change, 23, 61-69. doi: 10.1016/j.gloenvcha.2012.08.003

4. Marlon, J. R., van der Linden, S., Howe, P. D., Leiserowitz, A., Woo, S. H. L., \& Broad, K. (2018). Detecting local environmental change: The role of experience in shaping risk judgments about global warming. Journal of Risk Research, 22, 936950. doi: 10.1080/3669877.2018.1430051

5. Myers, T. A., Maibach, E. W., Roser-Renouf, C., \& Akerlof, K. (2013). The relationship between personal experience and belief in the reality of climate change. Nature Climate Change, 3, 343-347. doi: 10.1038/nclimate1754

6. Reser, J. P., Bradley, G. L., \& Ellul, C. (2014). Encountering climate change: 'Seeing' is more than 'Believing' Wiley Interdisciplinary Reviews: Climate Change, 5, 521-537. doi:1002/wcc. 286

7. van der Linden, S. (2014). On the relationship between personal experience, affect and risk perception: The case of climate change. European Journal of Social Psychology, 44, 430-440. doi: 10.1002/ejsp.2008

8. Wolf, J., \& Moser, S. C. (2011). Individual understandings, perceptions, and engagement with climate change: Insights from in-depth studies across the world. WIREs Climate Change, 2, 547-568. doi: 10.1002/wcc.120 
9. Center for Research on Environmental Decisions and ecoAmerica (CRED). (2014). Connecting on climate: A guide to effective climate change communication. New York: Center for Research on Environmental Decisions and ecoAmerica.

10. Cullen, H. (2010). The weather of the future. New York: Harper Collins.

11. Intergovernmental Panel on Climate Change (IPCC). (2014). Fifth assessment synthesis report: Impacts, adaptation and vulnerability. Geneva, Switzerland. Intergovernmental Panel on Climate Change. New York, NY: Cambridge University Press.

12. Kolbert, E. (2006). Field notes from a catastrophe: Man, nature, and climate change. New York: Bloomsbury.

13. Hansen, J. (2009). Storms of my grandchildren. New York: Bloomsbury.

14. Moser, S. C. \& Dilling, L. (Eds.). (2007). Creating a climate for change: Communicating climate change and facilitating social change. Cambridge, UK: Cambridge University Press.

15. Moser, S. C. (2014). Communicating adaptation to climate change: The art and science of public engagement when climate change comes home. WIREs Climate Change, 5, 337-358. doi: 10.1002/wcc. 276

16. Mann, M. E. \& Kump, L. R. (2008). Dire predictions: Understanding global warming, the illustrated guide to the findings of the IPCC. New York: Pearson Education \& DK.

17. Nisbet, M. (Ed.). (2017). Oxford Research Encyclopedia of Climate Change Communication. New York, NY: Oxford University Press.

18. Stocker, T. F., Qin, D., Plattner, G.-K., Tignor, M., Allen, S. K., Boschung, A., ... Midgley, P. M. (Eds.). (2013). The physical science basis: Contribution of Working Group I to the Fifth Assessment Report of the Intergovernmental Panel on Climate Change. Cambridge, UK: Cambridge University Press.

19. Whitmarsh, L., O’Neill, S., \& Lorenzoni, I. (Eds.). (2011). Engaging the public with climate change. London, UK: Earthscan.

20. Akerlof, K., Maibach, E. W., Fitzgerald, D., Cedeno, A. Y. \& Neuman, A. (2013). Do people 'personally experience global warming, and if so how, and does it matter? Global Environmental Change, 23, 81-89. doi: 10.1016/j. gloenvcha.2012.07.006 
21. Clayton, S., \& Manning, C. (Eds.). (2018). Psychology and climate change: Human perceptions, impacts, and responses. London, UK: Academic Press.

22. Clayton, S., Devine-Wright, P., Stern, P., Whitmarsh, L., Carrico, A., Steg, L., \& Bonnes, M. (2015). Psychological research and global climate change. Nature Climate Change, 5, 640-646. doi: 10.1038/nclimate2622

23. Dessai, S., Adger, W. N., Hulme, M., Turnpenny, J., Kohler, J., \& Warren, R. (2004). Defining and experiencing dangerous climate change. Climatic Change, 64, 11-25. doi: 10.1023/B:CLIM.0000024781.48904.45

24. Spence, A., Poortinga, W., Butler, C., \& Pidgeon, N. F. (2011). Perceptions of climate change and willingness to save energy related to flood experience. Nature Climate Change, 1, 46-49. doi: 10.1038/NCLIMATE1059

25. Reser, J. P., Bradley, G. L., \& Ellul, M. C. (2012a). Coping with climate change: Bringing psychological adaptation in from the cold. In B. Molinelli \& V. Grimaldo (Eds.), Handbook of the psychology of coping: Psychology of emotions, motivations and actions (pp. 1-34). New York, NY: Nova Science Publishers.

26. Reser, J. P., Bradley, G. L., Glendon, A. I., Ellul, M. C. \& Callaghan, R. (2012b). Public risk perceptions, understandings and responses to climate change and natural disasters in Australia: 2010-2011 national survey findings. Gold Coast, Qld: National Climate Change Adaptation Research Facility. Retrieved from: www.nccarf.edu.au/publications/public-risk-perceptions-second-survey

27. Swim, J., Clayton, S., Doherty, T., Gifford, R., Howard, G., Reser, J., Stern, P., \& Weber, E. (2011). Psychological contributions to understanding and addressing global climate change. Special issue. American Psychologist, 66, 241-328. doi: $10.1037 / \mathrm{a} 0023220$

28. Weber, E. U. (2006). Experience-based and description-based perceptions of longterm risk: Why global warming does not scare us (yet). Climatic Change, 77, 103120. doi: $10.1007 / \mathrm{s} 10584-006-9060-3$

29. Weber, E. U. (2016). What shapes perceptions of climate change? New research since 2010. WIREs Climate Change, 7. 125-134. doi: 10.1002/wcc.377

30. Devine-Wright, P., Price, J., \& Leviston, Z. (2015). My country or my planet? Exploring the influence of multiple place attachments and ideological beliefs upon climate change attitudes and opinions. Global Climate Change, 30, 68-79. doi: 10.1016/j.gloenvcha.2014.10.012 
31. Hulme, M. (2009). Why we disagree about climate change: Understanding controversy, inaction, and opportunity. Cambridge, UK: Cambridge University Press.

32. Bell, P. A., Greene, T. C., Fisher, J. D., \& Baum, A. (2001). Environmental psychology $\left(5^{\text {th }}\right.$ ed.). New York: Harcourt College Publishers.

33. Hawkes, G., \& Rowe, G. (2008). A characterisation of the methodology of qualitative research on the nature of perceived risk: trends and omissions. Journal of Risk Research, 11, 617-643. doi: 10.1080/13669870701875776

34. McDonald, R. I. (2016). Perceived temporal and geographic distance and public opinion about climate change. In M. Nisbet (Ed.), The Oxford research encyclopedia of climate change communication. New York, NY: Oxford University Press.

35. Nielsen, J. O., \& D'haen, S. A. L. (2014). Asking about climate change: Reflections on methodology in qualitative climate change research published in Global Environmental Change since 2000. Global Environmental Change, 24, 402-409 doi: 10.1016/j.gloenvcha.2013.10.006

36. Roser-Renouf, C., \& Nisbet, M. (2008). The measurement of key behavioral science constructs in climate change research. International Journal of Sustainability Communication, 3, 37-95.

37. Atkinson, L. (2018). Portrayal and impacts of climate change in advertising and consumer campaigns. In M.C. Nisbet (Ed.), The Oxford research encyclopedia of climate change communication. New York, NY: Oxford University Press.

38. Gavin, N. T. (2018). TV and cable news coverage of climate change. In M. C. Nisbet (Ed.), The Oxford research encyclopedia of climate change communication. New York, NY: Oxford University Press.

39. O’Neill, S. (2018). Engaging with climate change imagery. In M. C. Nisbet (Ed.), The Oxford research encyclopedia of climate change communication. New York, NY: Oxford University Press.

40. Wang, S., Leviston, Z., Hurlstone, M., Lawrence, C., \& Walker, I. (2018). Emotions predict policy support: Why it matters how people feel about climate change. Global Environmental Change, 50, 25-40. doi: 10.1016/j.gloenvcha.2018.03.002

41. Hassan, R. (2008). The information society: Digital media and society series. Cambridge, U.K.: Polity Press.

42. Krotoski, A. (2013). Untangling the web. New York: Faber \& Faber. 
43. Nisbet, M. (Ed.). (2017). The Oxford research encyclopedia of climate change communication. New York, NY: Oxford University Press.

44. Pearce, W., Niederer, S., Ozkula, S.M., \& Querubin, N. S. (2019). The social media life of climate change: Platforms, publics, and future imaginaries. WIREs Climate Change, 10, e569-n/a. doi: 10.1002/wcc.569

45. Reser, J. P., \& Bradley. G. L. (2017). Fear appeals in climate change communication. In M. Nisbet (Ed.), The Oxford research encyclopedia of climate change communication (Vol. 2, pp. 609-646). New York, NY: Oxford University Press.

46. Wagner, W., \& Hayes, N. (2005). Everyday discourse and common sense: The theory of social representations. New York, NY: Palgrave Macmillan.

47. Lujala, P., \& Lein, H. (2020). The role of personal experiences in Norwegian perceptions of climate change. Norwegian Journal of Geography. Advance online publication. doi:10.1080/00291951.2020.1731850

48. Druckman, J. N., \& McGrath, M. C. (2019). The evidence for motivated reasoning in climate change preference formation. Nature Climate Change, 9, 111-119. doi: $10.1038 / \mathrm{s} 41558-018-0360-1$

49. Kunda, Z. (1990). The case for motivated reasoning. Psychological Bulletin, 108, $480-498$.

50. Altman, I., \& Wohlwill, J. F. (Eds.). (1983). Behavior and the natural environment. Human behavior and environment. Advances in theory and research series. Vol 6. New York: Plenum.

51. Altman, I., \& Christensen, K. (1990). Environment and behavior settings: Emergence of intellectual traditions: Human behavior and environment, Advances in theory and research, Vol II. New York: Plenum Press.

52. Berleant, A. (1997). Living in the landscape: Toward an aesthetics of environment. Lawrence, Kansas: University Press of Kansas.

53. Gobster, P. H., \& Hull, R. B. (2000). Restoring nature: Perspectives from the social sciences and humanities. Washington, D.C.: Island Press. doi:

10.1016/j.ecolecon.2003.07.004

54. Groat, L. (Ed). (1995). Readings in environmental psychology: Giving places meaning. New York: Academic Press. 
55. Manzo, L. C., \& Devine-Wright, P. (Eds.). (2014). Place attachment: Advances in theory, methods and applications. London, UK: Routledge.

56. O’Riordan, T. (Ed.). (1995). Perceiving environmental risks. San Diego, CA: Academic Press.

57. Pidgeon, N., Kasperson, R. E., \& Slovic, P. (Eds.). (2003). The social amplification of risk. New York: Cambridge University Press.

58. Slovic, P. (2000). The perception of risk. London: Earthscan.

59. Slovic, P. (2010). The feeling of risk: New perspectives on risk perception. London: Earthscan.

60. Stanford Encyclopedia of Philosophy Archive. (2015). Phenomenology. (http://plato.stanford.edu/entries/phenomenology)

61. Thomashow, M. (2002). Bringing the biosphere home. Cambridge, MA: MIT Press.

62. Ashworth, P., \& Chung, M. C. (Eds.). (2006). Phenomenology and psychological science: Historical and philosophical perspectives. New York: Springer.

63. Schultz, P. W. (2002). Inclusion with nature: Understanding the psychology of human-nature interactions. In P. Schmuck \& P.W. Schultz (Eds.), The psychology of sustainable development (pp. 61-78). New York: Kluwer.

64. Bohm, G., \& Tanner, C. (2019) Environmental risk perception: An introduction. In L. Steg \& J. I. M. DeGroot (Eds.), Environmental psychology (pp.15-25). Chichester, UK: Wiley.

65. Bostrom, A. (2015). Risk perception. In J. B. Holbrook (Ed.), Ethics, science, technology, and engineering: A global resource, Vol 3, (2 ${ }^{\text {nd }}$ ed, pp. 643-645). Farmington Hills, MI, USA: Macmillan Reference.

66. Carlton, S. J., \& Jacobson, S. K. (2013). Climate change and coastal environmental risk perception in Florida. Journal of Environmental Psychology, 130, 32-39. doi: 10.1016/j.jenvman.2013.08.038

67. Gifford, R. (2014). Environmental psychology: Principles and practice. Fifth edition. Coleville, WA: Optimal Books.

68. Lazo, J. K., Kinnell, J. C. \& Fisher, A. (2000). Expert and layperson perceptions of ecosystem risk. Risk Analysis, 20, 170-193. doi: 10.1111/0272-4332.202019 
69. Taylor, J. G., Stewart, T. R., \& Downton, M. (1988). Perceptions of drought in the Ogallala Aquifier region. Environment and Behavior, 20, 150-175. doi: $10.1177 / 0013916588202002$

70. Dervin, B., \& Naumer, C. M. (2009). Sense-making. In S. W. Littlejohn \& K. A. Foss (Eds.), Encyclopedia of communication theory (pp. 877-881). Thousand Oaks, CA: Sage.

71. Folkman, S. (Ed.). (2011). The Oxford handbook of stress and coping. New York: Oxford University Press.

72. Hilton, D. (2007). Causal explanation: From social perception to knowledge-based causal attribution. In A. W. Kruglanki \& E. T. Higgins (Eds.), Social psychology: Handbook of basic principles ( $2^{\text {nd }}$ ed., pp 232-253). New York: The Guilford Press.

73. Renn, O., \& Rohrmann, B. (Eds.). (2000). Cross-cultural risk perception: State and challenges. Boston, MA: Springer.

74. Ryghaug, M., Sorensen, K. H., \& Naess, R. (2011). Making sense of global warming: Norwegians appropriating knowledge of anthropogenic climate change. Public Understanding of Science, 20, 778-795. doi: 10.1177/0963662510362657

75. Weick, K., Surcliffe, K. M., \& Obstfeld, D. (2005). Organising and the process of sensemaking. Organizational Science, 16, 409-421. doi: 10.1287/orsc.1050.0133

76. White, P. A. (1990). Ideas about causation in philosophy and psychology. Psychological Bulletin, 108, 3-18. doi: 10.1037/0033-2909.108.1.3

77. Future of Humanity Institute. (2016). Existential risk: Frequently asked questions. Oxford: Future of Humanity Institute, Oxford University. Retrieved from http://www.existential-risk.org/faq.html

78. Kolbert, E. (2014). The sixth extinction: An unnatural history. New York: Bloombury.

79. Kolbert, E. (2006). Field notes from a catastrophe: Man, nature, and climate change. New York: Bloomsbury.

80. Kramer, M. W. (2017). Sensemaking. In C. R. Scott \& L. K. Lewis (Eds.), The international encyclopedia of organizational communication (pp. 1-10). New York: Wiley. 
81. Young, I. F., Sullivan, D., Stewart, S., \& Palitsky, R. (2018). The existential approach to place: Consequences for emotional experience. Journal of Environmental Psychology, 60, 100-109. doi: 10.1016/j.jenvp.2018.10.012

82. Wallace-Wells, D. (2019). The uninhabitable earth: Life after warming. New York: Penguin/Allen Lane.

83. Wolfe, S. E., \& Tubi, A. (2018). Terror Management Theory and mortality awareness: A missing link in climate response studies? WIREs Climate Change, 10, e566. doi 10.1002/wcc.566

84. Weber, E. U. (1997). Perception and expectation of climate change. In M. H. Bazerman, D. M. Messick, A. E. Tenbrunzel, \& K. A. Wade-Benzoni (Eds.), Environment, ethics, and behavior: The psychology of environmental valuation and degradation. San Francisco, CA: The New Lexington Press.

85. National Research Council. (1992). Global environmental change: Understanding the human dimensions. Washington, D.C.: National Academy of Sciences.

86. Tschakert, P., Barnett, J., Ellis, N., Lawrence, C., Tuana, N., New, M., ... Pannell, D. (2017). Climate change and loss, as if people mattered: values, places, and experiences. WIREs Climate Change, 8, 1. doi: 10.1002/wcc.476

87. United Nations Framework Convention on Climate Change [UNFCCC] (1992). Retrieved from http://unfccc.int/essential_background/items/2877.php

88. Poortinga, W., Whitmarsh, L., Steg, L., Bohm, G., \& Fisher, S. (2019). Climate change perceptions and their individual level determinants: A cross-European analysis. Global Climate Change, 55, 25-35. doi: 10.1016/j.gloenvcha.2019.01.007

89. Whitmarsh, L., \& Capstick, S. (2018). Perceptions of climate change. In S. Clayton \& C. Manning (Eds.), Psychology and climate change: Human perceptions, impacts, and responses. (pp. 13-33). London, UK: Academic Press.

90. NASA (2018) Global climate change: Weather vs. climate. Retrieved from https://climate.nasa.gov/resources/global-warming/

91. Intergovernmental Panel on Climate Change (IPCC) (2007) Climate change 2007: Impacts, adaptation and vulnerability: Contribution of working group II to the fourth assessment report of the Intergovernmental Panel on Climate Change. Cambridge, UK: Cambridge University Press. 
92. Hulme, M. (2009). Why we disagree about climate change: Understanding controversy, inaction, and opportunity. Cambridge, UK: Cambridge University Press.

93. Shneiderman, A., \& Boyarski, I. (2002). Natural and hybrid disasters - Causes, effects, and management. Topics in Emergency Medicine, 24, 1-25.

94. Breakwell, G. M. (2010). Models of risk construction: Some applications to climate change. WIREs Climate Change, 1, 857-870. doi: 10.1002/wcc.74

95. Dickert, S., Vastfjall, D., Mauro, R., \& Slovic, P. (2015). The feeling of risk: Implications for risk perception and communication. In H. Cho, T. Reimer, \& K. A. McComas (Eds.), The Sage handbook of risk communication (pp. 41-54). Thousand Oaks, CA: Sage.

96. McDaniels, T., Axelrod, L. J., \& Slovic, P. (1995). Characterising perception of ecological risk. Risk Analysis, 15, 575-588. doi: 10.1111/j.1539-6924.1995.tb00754.x

97. Slovic, P. (1987). Perception of risk. Science, 236, 280-285.

98. 100 Oppenheimer, M., \& Todorov, A. (2006). Global warming: The psychology of long term risk. Climatic Change, 77, 1-6. doi: 10.1007/s10584-006-9086-6

99. McPhillips, L. E., Chang, H., Chester, M. V., Depietri, Y., Friedman, E., ... Shiva, J. S. (2018). Defining extreme events: A cross-disciplinary review. Earth's Future, 6, 441-455. doi: 10.1002/2017EF000686

100. Stott, P. A., Allen, M., Christidis, N., Dole, R., Hoerling, M., Huntingford, C., ... Stone, D. (2013). Attribution of weather and climate related extreme events. In A. Ghassem, \& J. W. Hurrell (Eds.), Climate science for serving society: Research, modelling and prediction priorities. New York, NY: Springer.

101. Hansen, A. (2006). Tampering with nature: 'Nature' and the 'natural' in media coverage of genetics and biotechnology. Media, Culture, and Society, 28, 811-834. doi: $10.1177 / 0163443706067026$

102. Lee, T. M., Markowitz, E. M., Howe, P. D., Ko, C.-Y., \& Leiserowitz, A. A. (2015). Predictors of public climate change awareness and risk perception around the world. Nature Climate Change, 5, 1014-1020. doi: 10.1038/nclimate2728

103. Capstick, S., Whitmarsh, L., Poortinga, W., Pidgeon, N., \& Upham, P. (2015). International trends in public perceptions of climate change over the past quarter century. WIREs Climate Change, 6, 35-61. doi:10.1002/wcc.321. 
104. Leiserowitz, A. \& Smith, N. (2018). Affective imagery, risk perceptions, and climate change communication. In M. C. Nisbet (Ed.), The Oxford research encyclopedia of climate change communication. New York, NY: Oxford University Press.

105. Greenhill, M., Leviston, Z., Leonard, R., \& Walker, I. (2014). Assessing climate change beliefs: Response effects of question wording and response alternatives. Public Understanding of Science, 23, 947-965. doi: 10.1177/0963662513480117

106. Gustafson, A., Berquist, P., Leiserowitz, A., \& Maibach, E. (2019). A growing majority of Americans think global warming is happening and are worried. New Haven, CT: Yale Program on Climate Change Communication.

107. Shao, W., Garand, J. C., Keim, B. D., \& Hamilton, L. C. (2016). Science, scientists, and local weather: Understanding mass perceptions of global warming. Social Science Quarterly, 97, 1023-1057. doi: 10.1111/ssqu.12317

108. Sjoberg, L. (2000). Factors in risk perception. Risk Analysis, 20, 1-11.

109. Ryghaug, M., Sorensen, K.H., \& Naess, R. (2011). Making sense of global warming: Norwegians appropriating knowledge of anthropogenic climate change. Public Understanding of Science, 20, 778-795. doi:10.1111/0272-4332.00001

110. Swim, J., Clayton, S., Doherty, T., Gifford, R., Howard, G., Reser, J., Stern, P., \& Weber, E. (2011). Psychological contributions to understanding and addressing global climate change. Special issue. American Psychologist, 66, 241-328. doi: $10.1037 / \mathrm{a} 0023220$

111. Viscusi, W. K., \& Zeckhauser, R. J. (2015). The relative weights of direct and indirect experiences in the formation of environmental risk belief. Risk Analysis, 35, 318-331. doi: $10.1111 /$ risa.12271

112. Wachinger, G., Renn, O., Begg, C., \& Kuhlicke, C. (2013). The risk perception paradox - Implications for governance ad communication of natural hazards. Risk Analysis, 33, 1049-1065. doi: 10.1111/j.1539-6924.2012.01942.x

113. Weber, E. U. (2010). What shapes perceptions of climate change? WIREs Climate Change, 1 (3) 332-342. doi.org/ 10.1002/wcc.41

114. Weintrobe, S. (Ed.). (2013). Engaging with climate change: Psychoanalytic and interdisciplinary perspectives. London: Routledge. 
115. Whitmarsh, L. (2009). What's in a name? Commonalities and differences in public understanding of "climate change" and "global warming". Public Understanding of Science, 18, 401-420. doi: 10.1177/0963662506073088

116. van der Linden, S. (2017). Determinants and measurement of climate change risk perception, worry, and concern. In M. Nisbet (Ed.), Oxford Encyclopedia of Climate Change Communication. New York, NY: Oxford University Press.

117. Slovic, P. (Ed) (2000). The perception of risk. London: Earthscan.

118. Weinstein, N. D. (1989). Effects of personal experience on self-protective behavior. Psychological Bulletin, 105, 31-50. doi: 10.1037//0033-2909.105.1.31

119. Halpern-Felsher, B. L., Millstein, S. G., Ellen, J. M., Adler, N. E., Tschann, J. M., \& Biehl, M. (2001). The role of behavioral experience in judging risks. Health Psychology, 20, 120-126. doi: 10.1037//0278-6133-.20.2.120

120. Hau, R., Pleskac, T. J., \& Herwig, R. (2010). Decisions from experience and statistical probabilities: Why they trigger different choices than a priori probabilities. Journal of Behavioral Decision Making, 23, 48-46.

121. Ruddell, D., Harlan, S. L., Grossman-Clarke, S., \& Chowell, G. (2012). Scales of perception: Public awareness and regional and neighbourhood climates. Climatic Change, 111, 581-607.

122. Sharma, U., \& Patt, A. (2012). Disaster warning response: the effects of different types of personal experience. Natural Hazards, 60, 409-423. doi: 10.1007/s11069011-0023-2

123. Howe, P. D., Boudet, H., Leiserowitz, A., \& Maibach, E. W. (2014). Mapping the shadow of experience of extreme weather events. Climatic Change, 127, 381-389. doi: 10.1007/s10584-014-1253-6

124. Brody, S. D., Zahran, S., Velditz, A., \& Grover, H. (2008). Examining the relationship between physical vulnerability and public perceptions of global climate change in the United States. Environment and Behavior, 40, 72-95. doi: $10.1177 / 0013916506298800$

125. Konisky, D. M., Hughes, L., \& Kaylor, C. H. (2016). Extreme weather events and climate change concern. Climatic Change, 134, 533-547. doi: 10.1007/s10584-0151555-3

126. Howe, P. D., Marlon, J. R., Mildenberger, M., \& Shield, B. S. (2019). How will climate change shape climate opinion? Environmental Research Letters, 14, 113001. doi: 10.1088/1748-9326/ab466a 
127. Carlton, J. S., Mase, A. S., Knutson, C. L., Lemos, M. C., Haigh, T., Todey, D. P., \& Prokopy, L. S. (2016). The effects of extreme drought on climate change beliefs, risk perceptions, and adaptation attitudes. Climatic Change, 135, 211-226. doi: $10.1007 / \mathrm{s} 10584-015-1561-5$

128. Gill, D. A., \& Richie, L.A. (2018). Contributions of technological and Natech disaster research to the social science disaster paradigm. In H. Rodriguez, W. Donner, \& J. E. Trainor (Eds.), Handbook of disaster research. (2 ${ }^{\text {nd }}$ ed., pp 39-60). New York: Springer. doi: 10.1080/13669870600717657

129. Joffe, H. (2003). Risk: From perception to social representation. British Journal of Social Psychology, 42, 55-73. doi: 10.1348/014466603763276126

130. Reser, J. P., \& Swim, J. (2011). Adapting to and coping with the threat and impacts of climate change. American Psychologist, 66, 277-289. doi: 10.1037/a0023412

131. Wagner, W., \& Hayes, N. (2005). Everyday discourse and common sense: The theory of social representations. New York, NY: Palgrave Macmillan.

132. Krotoski, A. (2013). Untangling the web. New York: Faber \& Faber.

133. Ogunbode, C. A., Demski, C., Capstick, S. B., \& Sposato, R. G. (2019). Attribution matters: Revisiting the link between extreme weather experience and climate change mitigation responses. Global Environmental Change, 54, 31-39. doi: 10.1016/j.gloenvcha.2018.11.005

134. Osberghaus, D. \& Demski, C. (2019). The causal effect of flood experience on climate change engagement: evidence from search requests for green electricity. Climatic Change. Advance online publication. doi:10.1007/s10584-019-02468-9

135. Egan, P. J., \& Mullin, M. (2012). Turning personal experience into political attitudes: The effect of local weather on Americans' perceptions of global warming. The Journal of Politics, 74, 796-809. doi: 10.1017/S0022381612000448

136. Ray, A., Hughes, L., Konisky, D. M., \& Kaylor, C. (2017). Extreme weather exposure and support for climate change adaptation. Global Environmental Change, 46, 104113. doi: 10.1016/j.gloenvcha.2017.07.002

137. Zanocco, C., Boudet, H., Nilson, R., Satei, H., Whitley, H., \& Flora, J. (2018). Place, proximity, and perceived harm: Extreme weather events and views about climate change. Climatic Change, 149, 349-365. doi: 10.1007/s10584-018-2251-x 
138. Broomell, S. B., Budescu, D. V., \& Por, H. H. (2015). Personal experience with climate change predicts intentions to act. Global Environmental Change, 32, 67-73. doi: 10.1016/j.gloenvcha.2015.03.001

139. Albright, E. A., \& Crow, D. (2019, online). Beliefs about climate change in the aftermath of extreme flooding. Climatic Change, 155, 1-17. doi: 10.1007/s10584-019$02461-2$

140. Lang, C., \& Ryder, J. D. (2016). The effect of tropical cyclones on climate change engagement. Climatic Change, 135, 652-638. doi: 10.1007/s10584-015-1590-0

141. Lyons, B. A., Hasell, A., \& Stroud, N. J. (2018). Enduring extremes? Polar vortex, drought, and climate change beliefs. Environmental Communication, 12, 876-894. doi: 10.1080/17524032.2018.1520735

142. Marquart-Pyatt, S. T., McCright, A. M., Dietz, T., \& Dunlap. R. E. (2014). Politics eclipses climate extremes for climate change perceptions. Global Environmental Change, 29, 246-257. doi: 10.1016/j.gloenvcha.201.10.004

143. McCright, A. M., Dunlap, R.E., \& Xiao, C. (2014). The impacts of temperature anomalies and political orientation on perceived winter warming. Nature Climate Change, 4, 1077-1081. doi: 10.1038/NCLIMATE2443

144. Osberghaus, D., \& Kühling, J. (2016). Direct and indirect effects of weather experiences on life satisfaction - which role for climate change expectations? Journal of Environmental Planning and Management, 59, 2198-2230. doi: 10.1080/09640568.2016.1139490

145. Palm, R., Lewis, G. B., \& Feng, B. (2017). What causes people to change their opinion about climate change? Annals of the Association of Geographers, 107, 883896. doi: 10.1080/24694452.2016.1270193

146. Sisco, M. R., Bosetti, V., \& Weber, E. U. (2017). When do extreme weather events generate attention to climate change? Climatic Change, 143, 227-241. doi: $10.1007 / \mathrm{s} 10584-017-1984-2$

147. Le Dang, H., Li, E., Nuberg, I., \& Bruwer, J. (2014). Farmers' perceived risks of climate change and influencing factors: A study in the Mekong Delta, Vietnam. Environmental Management, 54, 331-345. doi: 10.1007/s00267-014-0299-6

148. Oakes, L. E., Ardoin, N. M., \& Lambin, E. F. (2016). "I know, therefore I adapt?" Complexities of individual adaptation to climate-induced forest dieback in Alaska. Ecology and Society, 21, 40. doi: 10.5751/ES-08464-210240

149. Ogunbode, C.A., Liu, Y., \& Tausch, N. (2017). The moderating role of political affiliation in the link between flooding experience and preparedness to reduce energy use. Climatic Change, 145, 445-458. doi: 10.1007/s10584-017-2089-7 
150. Ogunbode, C. A., Bohm, G., Capstick, S. B., Demski, C., Spence, A., \& Tausch, N. (2019). The resilience paradox: Flooding experience and climate change mitigation intentions. Climate Policy, 19, 703-715. doi: 10.1080/14693062.2018.1560242

151. Ung, M., Luginaah, I., Chuenpagdee, R., \& Campbell, G. (2018). First-hand experience of extreme climate events and household energy conservation in Coastal Cambodia. Climate and Development, 10, 471-480. doi: 10.1080/17565529.2017.1301865

152. Fownes, J. R., \& Allred, S. B. (2019). Testing the influence of recent weather on perceptions of personal experience with climate change and extreme weather in New York State. Weather, Climate and Society, 11, 134-157. doi: 10.1175WCAS-D-100107.1

153. Asugeni, J., MacLaren, D., Massey, P. D., \& Speare, R. (2015). Mental health issues from rising sea level in a remote coastal region of the Solomon Islands: Current and future. Australian Psychiatry, 23, 22-25. doi: 10.1177/1039856215609767

154. Boon, H.J. (2016) Perceptions of climate change risk in four disaster-impacted rural Australian towns. Regional Environmental Change, 16, 137-149. doi: 10.1007/s10113-014-0744-3

155. Hamilton-Webb, A., Naylor, R., Manning, L., \& Conway, J. (2017a). 'Living on the edge': using cognitive filters to appraise experience of environmental risk. Journal of Risk Research, 22, 303-319. doi:10.1080/13669877.2017.1378249

156. Vulturius, G., André , K., Gerger Swartling, A., Brown, C., Rounsevell, M. D. A., Blanco, V. (2018). The relative importance of subjective and structural factors for individual adaptation to climate change by forest owners in Sweden. Regional Environmental Change, 18, 511-520. doi: 10.1007/s10113-017-1218-1

157. Babutsidze, Z., Bradley, G., Chai, A., Dietz, T., Hales, R. ...Nesta, L. (2018). Public perceptions and rsponses to climate change in France: Research report. Nice, France: Universite Cote d'Azur.

158. van der Linden, S. (2015). The social-psychological determinants of climate change risk perceptions: Toward a comprehensive model. Journal of Environmental Psychology, 41, 112-124. doi: 10.1016/j.jenvp.2014.11.012

159. Deng, Y., Wang, M., \& Yousefpour, R. (2017). How do people's perceptions and climatic disaster experiences influence their daily behaviors regarding adaptation to climate change? - a case study among young generation. Science of the Total Environment, 581-582, 840-847. doi: 10.1016/j.scitotenv.2017.01.022

160. Lujala, P., Lein, H., \& Rød, J. K. (2015). Climate change, natural hazards, \& risk perception: The role of proximity and personal experience. Local Environment, 20, 489-509. doi: 10.1080/13549839.2014.887666 
161. Zaval, L., Keenan, E. A., Johnson, E. J., \& Weber, E. U. (2014). How warm days increase belief in global warming. Nature Climate Change, 4, 143-147. doi: 10.1038/nclimate2093

162. Besel, R. D., Burke, K., \& Christos, V. (2017). A life history approach to perceptions of global climate change risk: Young adult's experiences about impacts, causes, and solutions. Journal of Risk Research, 20, 61-75. doi:

10.1080/13669877.2015.1017830162.

163. Tuan, Y. (1974). Topophilia: A study of environmental perception, attitude, and values. Englewood Cliffs, NJ: Prentice-Hall.

164. Berquist, M., Nilsson, A., \& Schultz, P. W. (2019). Experiencing a severe weather event increases concern about climate change. Frontiers in Psychology, 10, 220. doi: 10.3389/fpsyg.2019.00220

165. Taylor, A. L., Desai, S., \& Bruine de Bruin, W. (2014). Public perception of climate risk and adaptation in the UK: A review of the literature. Climate Risk Management, 4-5, 1-16. doi: 10.1016/j.crm.2014.09.001

166. Oxford University Press (2002) Shorter Oxford English Dictionary, Fifth Edition, Vol 1. New York: Oxford University Press.

167. Stevens, S. S. (1935). The operational definition of psychological constructs. American Journal of Psychology, 47, 323-330. doi: 10.1037/h0056973

168. Alston, W. P. (2000). Empiricism. In Concise Routledge encyclopedia of philosophy (pp. 239-240). New York: Routledge.

169. Bonaiuto, P., Giannini, M., \& Biasi, V. (2003). Perception theories and environmental experience. In M. Bonnes, T. Lee, \& M. Bonaiuto (Eds.), Psychological theories for environmental issues (pp.95-135). Aldershot, England: Ashgate.

170. Kaplan, R., \& Kaplan, S. (1989). The experience of nature: A psychological perspective. Cambridge, UK: Cambridge University Press.

171. Leff, H. L. (1978). Experience, environment, and human potentials. New York: Oxford University Press.

172. Werner, C. M., \&. Altman, I. (2000). Humans and nature: Insights from a transactional view. In S. Wapner, J. Demick, T. Yamamoto, \& H. Minami (Eds.), Theoretical perspectives in environment-behavior research (pp. 21-37). New York: Kluwer Academic/Plenum. 
173. Lazarus, R. S., \& Launier, R. (1978). Stress-related transactions between person and environment. In L. A. Pervin \& M. Lewis (Eds.), Perspectives in interactional psychology (pp. 287-327). New York: Plenum.

174. Neisser, U. (1976). Cognition and reality: Principles and implications of cognitive psychology. San Francisco: W.H. Freeman.

175. Werner, C. M., Brown, B. B., \& Altman, I. (2002). Transactionally oriented research: Examples and strategies. In R.B. Bechtel \& A. Churchman (Eds.), Handbook of environmental psychology. New York: Wiley.

176. Slovic, P. (2016) Understanding perceived risk: 1978-2015. Environment: Science and Policy for Sustainable Development, 58, 25-29.

177. Bruner, J. (1986). Actual minds: Possible worlds. Cambridge MA: Harvard University Press.

178. Bruner, J. (1990). Acts of meaning. Cambridge, MA: Harvard University Press.

179. Piaget, J. (1955). The language and thought of the child. New York: Meridian Books.

180. Pollio, H. R., Henley, T. B. \& Thompson, C. J. (1997). The phenomenology of everyday life: Empirical investigations of human experience. New York: Cambridge University Press. doi.org/10.1017/CBO9780511752919

181. Robin, L. (2018). Environmental humanities and climate change: Understanding humans geologically and other life forms ethically. WIREs Climate Change, 9, e499. doi: 10.1002/wcc.499

182. Schwarz, N., \& Clore, G. L. (2007). Feelings and phenomenal experiences. In A. W. Kruglanski \& E. Tory Higgins (Eds.), Social psychology: Handbook of basic principles (2d. ed., pp. 385-407). New York: Guilford.

183. Abbot, D., \& Wilson, G. (2015). Climate change: Lived experience, policy and public action. International Journal of Climate Change Strategies and Management, 6, 518. doi: 10.1108/IJCCSM-04-2013-0040

184. Seamon, D. (2000). A way of seeing people and place. Phenomenology in environment behavior research. In S. Wapner, J. Demick, T. Yamamoto, \& H. Minami (Eds.), Theoretical perspectives in environment-behavior research (pp. 149178). New York: Plenum.

185. Seamon, D. (2018). Life takes place: Phenomenology, lifeworlds, and place making. New York: Routledge. 
186. Cunsolo, A., \& Ellis, N. R. (2018). Ecological grief as a mental health response to climate change loss. Nature Climate Change, 8, 275-281. doi: 10.1038/s41558-0180092-2

187. Doherty, T. J. (2018). Individual impacts and resilience. In S. Clayton \& C. Manning (Eds.), Psychology and climate change: Human perceptions, impacts, and responses (pp. 245-266). London, UK: Academic Press.

188. Lertzman, R. (2015). Environmental melancholia: Psychoanalytic dimensions of engagement. London: Routledge.

189. Tschakert, P., Ellis, N. R., Anderson, C., Kelly, A., \& Obeng, J. (2019). One thousand ways to experience loss: A systematic analysis of climate-related intangible harm from around the world. Global Climate Change, 55, 58-72. doi: 10.1016/j.gloenvcha.2018.11.006

190. Steg, L., \& Vlek, C. (2009). Encouraging pro-environmental behaviour: An integrative review and research agenda. Journal of Environmental Psychology, 29, 307-317. doi: 10.1016/j.jenvp.2008.10.004

191. Stern, P. C. (2000). New environmental theories: Toward a coherent theory of environmentally significant behavior. Journal of Social Issues, 56, 407-424. doi: $10.1111 / 0022-4537.00175$

192. Deci, E. L., \& Ryan, R. M. (2002). Handbook of self-determination research. New York: University of Rochester Press.

193. Krosnick, J. A., Holbrook, A. L., Lowe, L., \& Visser, P. S. (2006). The origins and consequences of democratic citizens' policy agendas: A study of popular concern about global warming. Climatic Change, 77, 7-43. doi: 10.1007/s10584-006-9068-8

194. Lazarus, R. S. (1991). Emotion and adaptation. New York: Oxford University Press.

195. Viscusi, W. K., \& Zeckhauser, R. J. (2015). The relative weights of direct and indirect experiences in the formation of environmental risk belief. Risk Analysis, 35, 318-331. doi: $10.1111 /$ risa.12271

196. Lloyd, E. A. \& Oreskes, N. (2018). Climate change attribution: When is it appropriate to accept new methods. Earth's Future, 6, 311-325. doi: 10.1002/2017EF000665

197. Ornes, S. (2018). How does climate change influence extreme weather? Impact attribution research. $P N A S, 115,8232-8235$. doi: 10.1073/pnas. 1811393115 
198. Argyris, N., Ferretti, V., French, S., Guikema, S., \& Montibeller, G. (2019). Advances in spatial risk analysis. Risk Analysis, 39, 1-8. doi: 10.111/risa.13260

199. Zahran, S., Brody, S., Grovenor, H., \& Velditz, A. (2006). Climate change vulnerability and policy support. Society and Natural Resources, 19, 771-789. doi:10.1080/08941920600835528

200. van Valkengoed, A. M. \& Steg, L. (2018). Meta-analyses of factors motivating climate change adaptation behavior. Nature Climate Change, 9, 158-163. doi: $10.1038 / \mathrm{s} 41558-018-0371-y$

201. Intergovernmental Panel on Climate Change (IPCC). (2018). Global Warming of $1.5^{\circ} \mathrm{C}$. An IPCC Special Report on the impacts of global warming of $1.5^{\circ} \mathrm{C}$ above preindustrial levels and related global greenhouse gas emission pathways, in the context of strengthening the global response to the threat of climate change, sustainable development, and efforts to eradicate poverty. Geneva, Switzerland, Intergovernmental Panel on Climate Change.

202. U.S. Global Change Research Program (USGCRP) (2017) The impacts of climate change on human health in the United States: A scientific assessment. Washington, DC.

203. Douglas, M., \& Wildavsky, A. (1982). Risk and culture. Berkeley: University of California Press.

204. Shi, J., Visschers, V. H. M., \& Siegrist, M. (2015). Public perception of climate change: The importance of knowledge and cultural worldviews. Risk Analysis, 35, 2183-2201. doi: 10.1111/risa.12406

205. MacKellar, D. (1911). The closed door. Poem: 'My country'. Melbourne, Vic: Australian Authors' Agency.

206. Reser, J. P., Bradley, G. L., Glendon, A. I., Ellul, M. C., \& Callaghan, R. (2012c). Public risk perceptions, understandings, and responses to climate change and natural disasters in Australia and Great Britain. Gold Coast, Qld: Griffith University, National Climate Change Adaptation Research Facility. Retrieved from: www.nccarf.edu.au/publications/public-risk-perceptions-final

207. Elal, G., \& Slade, P. (2005). Traumatic Exposure Severity Scale (TESS): A measure of exposure to major disasters. Journal of Traumatic Stress, 18, 213-220. doi: $10.1002 /$ jts. 20030

208. Reser, J. P., Bradley, G. L., Glendon, A. I., Ellul, M. C. \& Callaghan, R. (2012). Public risk perceptions, understandings and responses to climate change and natural 
disasters in Australia: 2010-2011 national survey findings. Gold Coast, Qld: National Climate Change Adaptation Research Facility.

www.nccarf.edu.au/publications/public-risk-perceptions-second-survey

209. Reser, J. P., Bradley, G. L., \& Ellul, M. C. (2012). Coping with climate change:

Bringing psychological adaptation in from the cold. In B. Molinelli \& V. Grimaldo (Eds.), Handbook of the psychology of coping: Psychology of emotions, motivations and actions (pp. 1-34). New York, NY: Nova Science Publishers.

210. Brulle, R. J., Carmichael, J., \& Jenkins, J. C. (2012). Shifting public opinion on climate change: an empirical assessment of factors influencing concern over climate change in the U.S., 2002-2010. Climatic Change, 114, 169-188. doi.1007/s10584012-0403-y

211. Desai, S., \& Sims, C. (2010). Public perceptions of drought and climate change in southeast England. Environmental Hazards, 9, 340-357. doi: 10.3763/ehaz.2010.0037

212. Hornsey, M. J., Harris, E. A., Bain, P. G., \& Fielding, K. S. (2016). Meta-analyses of the determinants and outcomes of belief in climate change. Nature Climate Change, 6, 622-627. doi: 10.1038/nclimate2943

213. Howe, P. D. (2019). Feeling the heat is not enough. Nature Climate Change, 9, 353357. doi: 10.1038/s41558-019-0464-2

214. Larcom, S., She, P-W., \& van Gevelt, T. (2019). The UK summer heatwave of 2018 and public concern over energy security. Nature Climate Change, 9, 370-373. doi: $10.1038 / \mathrm{s} 41558-019-0460-6$

215. Tanner. A., \& Arvai, J. (2018). Perceptions of risk and vulnerability following exposure to a major natural disaster. Risk Analysis, 38, 548-561. doi:

$10.1111 /$ risa.12851

216. Bell, P. A., Greene, T. C., Fisher, J. D., \& Baum, A. (2001). Environmental psychology $\left(5^{\text {th }}\right.$ ed.). New York: Harcourt College Publishers.

217. Dodgen, D., Donato, D., Dutta, T., Kelly, N., La Greca, A., Morganstein, J., ... Shimamoto, M. (2016). Mental health and well-being. In U.S. National Climate Assessment/U.S. Global Change Research Program (USCGRP) Climate and Health Assessment: Interagency special report on the impacts of climate change on human health in the United States. (pp. 217-246). Washington, DC: U.S. National Climate Assessment/U.S. Global Change Research Program.

218. Norris, F. H., Friedman, M. J., Watson, P. J., Byrne, C. M., Diaz, E. \& Kaniasty, K. (2002). 60,000 disaster victims speak: Part 1. An empirical review of the empirical literature, 1981-2001. Psychiatry: Interpersonal and Biological Processes, 65, 207239. doi.org/10.1521/psych.65.3.207.20173 
219. Weisbecker, I. (Ed.). (2011). Climate change and human well-being: Global challenges and opportunities. New York: Springer.

220. Geertz, C. (1973). The interpretation of cultures. New York: Harper Collins.

221. Geertz, C. (1983). Local knowledge: Further essays in interpretive anthropology. New York, Basic Books

222. Arnold, A. (2018). Climate change and story-telling: Narrative and cultural meaning in environmental communication. New York: Palgrave Macmillan.

223. Boulton, E. (2016). Climate change as a hyperobject: A critical review of Timothy Morton's reframing narrative. WIREs Climate Change, 7, 772-785. doi:10.1002/wcc.410

224. Casimir, M. J. (Ed.). (2008). Culture and the changing environment: Uncertainty, cognition and risk management in cross-cultural perspective. New York: Berghahn Books.

225. Crate, S. A., \& Nuttal, M. (Eds.). (2009). Anthropology and climate change: From encounters to actions. Walnut Creek, CA: Left Coast Press.

226. Hamblyn, R. (2009). Narrative of elemental change. Journal of Historical Geography, 35, 215-222. doi: 10.1016/j.jhg.208.09.005

227. Bandura, A. (1997). Self-efficacy: The exercise of control. New York: Freeman.

228. Pribram, K. H. (Ed.). (1969). Adaptation: Selected readings. Harmondsworth, England: Penguin Books.

229. Bradley, G. L., \& Reser, J. P. (2017). Adaptation processes in the context of climate change: A social and environmental psychology perspective. Journal of Bioeconomics, 19, 29-51. doi: 0.1007/s10818-016-9231-x

230. Perrin, A., \& Jiang, J. (2018). About a quarter of U.S. adults say they are 'almost constantly' online. Pew Research Center. Retrieved from https://www.pewresearch.org/fact-tank/2019/07/25/americans-going-online-almostconstantly/

231. Austin, A., Barnard, J., \& Hutcheon, N. (2015). Media consumption forecasts 2015. Las Angeles, CA: ZenithOptimedia. 
232. Wang, S., Corner, A., Chapman, D., \& Markowitz, E. (2017). Public engagement with climate imagery in a changing digital landscape. WIREs Climate Change, 9, e509. doi: 10.1002/wcc.509

233. Kruglanski, A. W. (1989). The psychology of being right: The problem of accuracy in social perception and cognition. Psychological Bulletin, 106, 395-409.

234. Carmi, N. \& Kimhi, S. (2015) Further than the eye can see: Psychological distance and perception of environmental threats. Human and Ecological Risk Assessment: An International Journal, 21,2239-2257. doi: 1080/10807039.2015.1046419

235. McDonald, R. I., Chai, H. Y., \& Newell, B. R. (2015). Personal experience and the psychological distance of climate change: An integrative review. Journal of Environmental Psychology, 44, 109-118. doi: 10.1016/j.jenvp.2015.10.003

236. McDonald, R. I. (2016). Perceived temporal and geographic distance and public opinion about climate change. In M. Nisbet (Ed.), Oxford research encyclopedia of climate change communication. Oxford, UK: Oxford University Press.

237. O'Reilly, J. (2018). The substance of climate: Material approaches to nature under environmental change. WIREs, 9, doi: 10.1002/wee.550

238. Schuldt, J. P., Rickard, L. N., \& Yang, Z. J. (2018). Does reduced psychological distance increase climate engagement? On the limits of localizing climate change. Journal of Environmental Psychology, 55, 147-153. doi: 10.1016/j.jenvp.2018.02.001

239. Spence, A., Poortinga, W., \& Pidgeon, N. (2012). The psychological distance of climate change. Risk Analysis, 32, 957-972. doi: 10.1111/j.1539-6924.2011.01695.x

240. Trope, Y., \& Liberman, N. (2010). Construal level theory of psychological distance. Psychological Review, 117, 440-463. doi: 10.1037/a0018963

241. Brown, V. A., Harris, J. A., \& Russell, J. Y. (2010). Tackling wicked problems: Through the transdisciplinary imagination. London, UK: Earthscan.

242. Weber, U., \& Stern, P. (2011). Public understanding of climate change in the United States. American Psychologist, 66, 315-328. doi: 10.1037/a0023253

243. Evans, G. W. (2019). Projected behavioral impacts of global climate change. Annual Review of Psychology, 70, 449-474. doi: 10.1146/annurev-psych-010418-103023

244. Ornstein, R., \& Ehrlich, P. (1989). New world, new mind: Moving toward conscious evolution. New York: Touchstone. 
245. Schmidt, A., Ivanova, A., \& Schafer, M. S. (2013). Media attention for climate change around the world: A comparative analysis of newspaper coverage in 27 countries. Global Environmental Change, 23, 1233-1248. doi: 10.1016/j.gloenvcha.2013.07.020

246. Tversky, A., \& Kahneman, D. (1974). Judgment under uncertainty: Heuristics and biases, Science, 185, 1124-1131. doi: 10.1126/science.185.4157.1124

247. Floyd, D. L., Prentice-Dunn, S., \& Rogers, R. W. (2000). A meta-analysis of research on protection motivation theory. Journal of Applied Social Psychology, 30, 407-429. doi: 10.1111/j.1559-1816.2000.tb02323.x

248. Gardner, G. T., \& Stern, P. C. (2002). Environmental problems and human behavior. $\left(2^{\text {nd }}\right.$ ed.). Boston, MA: Pearson Custom Publishing.

249. Gardner, G. T., \& Stern, P. C. (2008). The short list. Environment, 50, 13-24. doi: 10.1061/(ASCE)LM.1943-5630.0000230

250. Adler, C. E. \& Hadorn, G. H. (2014). The IPCC and treatment of uncertainties: topics and sources of disensus. WIREs Climate Change, 5, 663-676. doi: 10.1002/wcc.297

251. National Oceanic and Atmospheric Administration (NOAA), (2018) Global climate report. Asheville, NC: USA.

252. Rousseau, D. R., \& Gunia, B. C. (2016). Evidence-based best practice: The psychology of EBP implementation. Annual Review of Psychology, 67, 667-692. doi: 10.1146/annurev-psych-122414-033336.

253. Callegaro, M. Baker, R., Bethlehem, J., Goritz, A.S. Krosnick, J. \& Lavrakas, P.J. (Eds.) (2014). Online panel research: History, concepts, applications and a look at the future. New York: Wiley.

254. Nielsen, J. O., \& D'haen, S. A. L. (2014). Asking about climate change: Reflections on methodology in qualitative climate change research published in Global Environmental Change since 2000. Global Environmental Change, 24, 402-409 doi: 10.1016/j.gloenvcha.2013.10.006

255. Stott, P. A., Christidis, N., Otto, F. E. L., Sun, Y., Vanderlinden, J-P., van Oldenborgh, G. J., Vautard, R., von Storch, H., Walton, P. Yiou, P., \& Zwiers, F. (2015). Attribution of extreme weather and climate change-related events. WIREs Climate Change, 7, 23-41. doi: 10.1002/wcc.380 
256. National Research Council. (2005). Environmentally significant individual behavior. Decision making for the environment: Social and behavioral science research priorities. Washington, DC: The National Academies Press.

257. Yusof, K., \& Gabrys, J. (2011). Climate change and the imagination. WIREs Climate Change, 2, 516-534. doi: 10.1002/wcc.117 